\title{
Pharmacological Acute Migraine Treatment Strategies: Choosing the Right Drug for a Specific Patient
}

\author{
Irene Worthington ${ }^{1}$, Tamara Pringsheim ${ }^{3}$, Marek J. Gawel ${ }^{1,8,9}$, \\ Jonathan Gladstone ${ }^{1,2}$, Paul Cooper ${ }^{4}$,Esma Dilli ${ }^{5}$, Michel Aube ${ }^{6}$, \\ Elizabeth Leroux ${ }^{7}$, Werner J. Becker ${ }^{3}$ on behalf of the Canadian Headache \\ Society Acute Migraine Treatment Guideline Development Group
}

\begin{abstract}
Background: In our targeted review (Section 2), 12 acute medications received a strong recommendation for use in acute migraine therapy while four received a weak recommendation for use. Strong recommendations were made to avoid use of two other medications, except for exceptional circumstances. Two anti-emetics received strong recommendations for use as needed. Objective: To organize the available acute migraine medications into acute migraine treatment strategies in order to assist the practitioner in choosing a specific medication(s) for an individual patient. Methods: Acute migraine treatment strategies were developed based on the targeted literature review used for the development of this guideline (Section 2), and a general literature review. Expert consensus groups were used to refine and validate these strategies. Results: Based on evidence for drug efficacy, drug side effects, migraine severity, and coexistent medical disorders, our analysis resulted in the formulation of eight general acute migraine treatment strategies. These could be grouped into four categories: 1) two mild-moderate attack strategies, 2) two moderate-severe attack or NSAID failure strategies, 3 ) three refractory migraine strategies, and 4) a vasoconstrictor unresponsive-contraindicated strategy. In addition, strategies were developed for menstrual migraine, migraine during pregnancy, and migraine during lactation. The eight general treatment strategies were coordinated with a "combined acute medication approach" to therapy which used features of both the "stratified" and the "step care across attacks" approaches to acute migraine management. Conclusions: The available medications for acute migraine treatment can be organized into a series of strategies based on patient clinical features. These strategies may help practitioners make appropriate acute medication choices for patients with migraine.
\end{abstract}

RÉSUMÉ: Stratégies de traitement pharmacologique de la crise aiguë de migraine : choisir la bonne médication pour un patient donné. Contexte : Dans notre révision ciblée (section 2), 12 médicaments de phase aiguë ont reçu une forte recommandation pour leur utilisation dans le traitement de la crise aiguë de migraine et 4 ont reçu une recommandation faible. Une forte recommandation a été émise contre l'utilisation de 2 autres médicaments, sauf dans des circonstances exceptionnelles. Deux médicaments antiémétiques sont fortement recommandés pour utilisation au besoin. Objectif : Le but de l'étude était d'organiser la médication disponible pour le traitement de la crise aiguë de migraine en stratégies de traitement afin d'aider le médecin à choisir un médicament spécifique pour un patient donné. Méthode : Une revue ciblée de la littérature ainsi qu'une revue générale de la littérature ont été utilisées pour développer des stratégies de traitement de la crise aiguë de migraine et pour élaborer ces lignes directrices (section 2). Des groupes de consensus expert ont été utilisés pour raffiner et valider ces stratégies. Résultats : L'élaboration de 8 stratégies générales de traitement de la crise aiguë de migraine résulte de notre analyse basée sur des preuves de l'efficacité de la médication et de ses effets secondaires, la sévérité de la migraine et la présence de comorbidités. Elles peuvent être regroupées en 4 catégories : 1) deux stratégies pour les crises légères à modérées ; 2) deux stratégies pour les crises modérées à sévères ou si échec des AINS ; 3) trois stratégies pour la migraine réfractaire et 4) une stratégie si échec ou contreindication au traitement par un vasoconstricteur. De plus, des stratégies ont été élaborées pour la migraine menstruelle, la migraine pendant la grossesse et pendant la lactation. Les 8 stratégies de traitement général ont été coordonnées avec une approche combinée pour la médication de phase aiguë qui utilisait des caractéristiques de l'approche stratifiée et de l'approche par étapes pour toute crise pour le traitement de la crise aiguë de migraine. Conclusions : Les médicaments qui sont disponibles pour traiter la crise aiguë de migraine peuvent être organisés en stratégies de traitement basées sur le tableau clinique que présente le patient. Ces stratégies peuvent aider le médecin à faire des choix appropriés de médication pour traiter les patients qui souffrent de migraine.

Can J Neurol Sci. 2013; 40: Suppl. 3 - S33-S62

Finding an effective acute medication may be relatively simple for many patients with migraine, particularly those with attacks of mild or moderate severity. They may find, for example, that ibuprofen works well for them. Others may need to try a number of prescription medications before they find one that is satisfactory.

In Section 2, 18 acute migraine medications and two adjunctive medications were evaluated. Twelve acute
From ${ }^{1}$ Sunnybrook Health Sciences Centre, Toronto, Ontario; ${ }^{2}$ Gladstone Headache Clinic, Toronto, Ontario; ${ }^{3}$ University of Calgary and the Hotchkiss Brain Institute, Calgary, Alberta; ${ }^{4}$ University of Western Ontario, London, Ontario; ${ }^{5}$ University of British Columbia, Vancouver, British Columbia; ${ }^{6} \mathrm{McGill}$ University, Montreal,

Quebec, ${ }^{7}$ University of Montreal, Montreal, Quebec; ${ }^{8}$ Rouge Valley Health System -

Centenary, Toronto, Ontario; ${ }^{9}$ Women's College Hospital, Toronto, Ontario, Canada. Received June 9, 2013. Final Revisions Submitted June 22, 2013.

Correspondence to: W.J. Becker, Division of Neurology, 12th Floor, Foothills Hospital, 1403 29th St NW, Calgary, Alberta, T2N 2T9, Canada. 
medications received a strong recommendation for use in acute migraine therapy (Table 1). Four acute medications received a weak recommendation for use, with three of these NOT recommended for routine use (ergotamine, opioids including codeine-containing medications, and tramadol-containing medications). Strong recommendations were made to avoid use of butorphanol nasal spray and butalbital-containing medications, with use only under exceptional circumstances. Two oral anti-emetics, metoclopramide and domperidone, received a strong recommendation for use with acute migraine attack medications where necessary.

\section{Acute Migraine Treatment Approaches and Strategies}

The goal of this section of the guideline is to provide additional guidance to the practitioner in choosing a medication for a specific patient, based upon the evidence-based review presented in Section 2, a general literature review, and expert consensus based on clinical experience.

Table 1: Medications for Acute Migraine Treatment Assessed in Section 2*

\begin{tabular}{l|l}
\hline Class, drug, (route) & Recommendation \\
\hline \multicolumn{1}{c}{ Recommended for use in episodic migraine** (Use) } \\
\hline $\begin{array}{l}\text { Triptans and other migraine-specific } \\
\text { medications: }\end{array}$ \\
\hline Almotriptan (oral) & Strong \\
\hline Eletriptan(oral) & Strong \\
\hline Frovatriptan (oral) & Strong \\
\hline Naratriptan (oral) & Strong \\
\hline Rizatriptan (oral) & Strong \\
\hline Sumatriptan (SC, oral, intranasal) & Strong \\
\hline Zolmitriptan (oral, intranasal) & Strong \\
\hline $\begin{array}{l}\text { Dihydroergotamine (DHE) (intranasal, SC } \\
\text { self-injection) }\end{array}$ & Weak \\
\hline Ergotamine (oral) & Weak (not recommended \\
& for routine use) \\
\hline ASA / NSAIDs: & \\
\hline ASA (oral) & Strong \\
\hline Diclofenac potassium (oral) & Strong \\
\hline Ibuprofen (oral) & Strong \\
\hline Naproxen sodium (oral) & Strong \\
\hline Other: & \\
\hline Acetaminophen (oral) & Strong \\
\hline Opioids and Tramadol): & \\
\hline Opioid (i.e., codeine)-containing & Weak (not recommended \\
medications (oral) & for routine use) \\
\hline Tramadol-containing medications (oral) & Weak (not recommended \\
& for routine use) \\
\hline Anti-emetics: & Strong \\
\hline Domperidone (oral) & Strong \\
\hline Metoclopramide (oral) & Not recommended for use in episodic migraine** \\
\hline & (Do not use)***: \\
\hline Butalbital-containing medications (oral) & Strong \\
\hline Butorphanol (intranasal) & \\
\hline & \\
\hline
\end{tabular}

*Utilizing GRADE criteria; **Migraine with headache on less than 15 days per month; ***Except under exceptional circumstances
Medication choice for a patient with migraine must be individualized, and various treatment approaches are proposed in the literature. ${ }^{1}$ In this guideline, we propose that the "stratified care" approach may be most appropriate for many patients with severe migraine attacks; while a modified "step care across attacks" approach may be more appropriate for many others with migraine. We have called this overall approach a "combined acute medication approach". Because it bases choice of acute migraine medication upon the patient's clinical features, and flexibly combines features of both the "stratified" and "step care across attacks" approaches, we feel it may be the best overall acute migraine treatment approach.

Although the term "strategy" has been used for "stratified", "step-care across attacks", and "step-care within attacks" approaches, we feel the term "approach" is more appropriate than "strategy" for these very general approaches to acute treatment. We use the term "strategy" in this guideline for more specific components of the therapeutic choices that must be made. Each of the strategies discussed in this guideline relates directly to a specific clinical situation, and to specific drugs (Table 2). In this way, we hope to provide therapeutic guidance beyond the three treatment approaches that have already been discussed in the medical literature. ${ }^{1}$

The factors that need to be considered when an acute medication is recommended for a patient are shown in Table 3. Some of these have already been mentioned in Section 1 under "General Principles of Acute Migraine Therapy".

\section{"Stratified" versus "step care" approaches}

Treatment approaches have already been defined and discussed in Section 1. "Stratified care", where the first acute medication recommended is tailored to the patient's attack severity or degree of disability, has been promoted as the best way to find the right medication for the patient quickly. This likely reduces the number of patients who become discouraged and become "lapsed consulters". A potential disadvantage of this approach is that a more expensive medication (e.g., a triptan) may be used long term by the patient when a less expensive medication (e.g., an NSAID) might have been effective.

\section{Table 2: Acute Migraine Treatment Strategies}

1. Mild-moderate attack strategies:

a. Acetaminophen strategy

b. NSAID strategy

2. Moderate-severe attack or NSAID failure strategies:

a. NSAID with triptan rescue strategy

b. Triptan strategy

3. Refractory migraine strategies:

a. Triptan - NSAID combination strategy

b. Triptan - NSAID combination with rescue medication strategy

c. Dihydroergotamine strategy

4. Vasoconstrictor unresponsive-contraindicated strategy

5. Menstrual migraine strategy

6. Migraine during pregnancy strategy

7. Migraine during lactation strategy 
The "step care across attacks" approach usually involves using "simple" analgesics (e.g., acetaminophen or NSAIDs) first, and "stepping up" to the triptans if necessary. This approach may result in more lapsed consulters, and in needless suffering as various ineffective medications are tried in turn.

In the "step care within attacks" approach, the patient takes an non-steroidal anti-inflammatory drugs (NSAID) or acetaminophen early in an attack, and "moves up" to a triptan several hours later if the first medication is ineffective. As all acute migraine medications are more likely to be effective if taken early in the attack, this can be a self-defeating approach, although some patients with slowly developing migraine attacks and those who can predict the severity of an oncoming attack with some degree of certainty may find it useful.

It is likely that no single treatment approach is ideal for all patients. In practice, many patients have already tried several non-prescription medications before consulting a physician, so a "step care across attacks" approach has already been started. For those who have not, careful patient education and the streaming of patients into an appropriate treatment approach and strategy based upon their clinical features may be most effective. Described below is a "combined" treatment approach. It includes an acute medication treatment "ladder" for those streamed to "step care across attacks". For each component or step, more details may be found regarding the medications recommended by going to the relevant strategy description later in this section.

\section{Combined acute medication approach for migraine attacks}

In this approach, treatment recommendations are based on attack severity and response to previously tried medications. Note that some patients may have more than one attack severity. In addition to attack severity, the overall structural features of the patient's usual migraine attack need to be considered when planning management (Table 3). These include:

\section{Table 3: Factors to be considered when recommending an acute migraine medication}

\begin{tabular}{|c|c|}
\hline Factor & Comment \\
\hline Patient response & $\begin{array}{l}\text { The response of a specific patient to medications cannot be predicted with certainty. Responses to medications used in the past } \\
\text { can help guide therapy. }\end{array}$ \\
\hline Evidence for efficacy & The quality of evidence available varies greatly for different medications. \\
\hline Tolerability & Side effects differ between different medications. \\
\hline $\begin{array}{l}\text { Co-existent medical and } \\
\text { psychiatric disorders }\end{array}$ & These may result in contraindications to some acute medications (e.g., vascular disease and vasoconstrictors). \\
\hline Pain intensity & $\begin{array}{l}\text { Patients with disabling pain intensity are more likely to require a "stratified approach" with early use of triptans or triptan- } \\
\text { NSAID combination. If pain builds up rapidly and peaks early in the attack, a medication with rapid absorption may be } \\
\text { necessary (e.g., SC sumatriptan, intranasal zolmitriptan, oral rizatriptan, etc). This may be particularly important for attacks } \\
\text { that are fully developed upon awakening. }\end{array}$ \\
\hline Attack duration & $\begin{array}{l}\text { Patients with long-lasting migraine attacks (lasting beyond } 24 \text { hours untreated) may be more prone to headache recurrence. A } \\
\text { triptan with a lower rate of headache recurrence (eletriptan, frovatriptan) or a triptan combined with an NSAID with a longer } \\
\text { half-life (e.g., naproxen sodium) may be helpful. }\end{array}$ \\
\hline $\begin{array}{l}\text { Associated migraine } \\
\text { symptoms - nausea and / } \\
\text { or vomiting }\end{array}$ & $\begin{array}{l}\text { These may indicate the need for a non-oral medication formulation, and / or an anti-emetic. This is particularly important for } \\
\text { patients with nausea and / or vomiting early in the attack. }\end{array}$ \\
\hline Early treatment & $\begin{array}{l}\text { All acute medications appear to be more effective when taken early in the migraine attack. A potentially effective medication } \\
\text { may be considered ineffective by the patient if it is taken only after the attack is fully developed. This becomes especially } \\
\text { important if a "step care within attacks" approach is being considered. The benefits of early treatment must be balanced } \\
\text { against the risk of medication overuse in patients with frequent migraine attacks. }\end{array}$ \\
\hline Consistency of response & $\begin{array}{l}\text { For patients with severe attacks, if the patient's, primary acute medication is not effective for every attack, a rescue medication } \\
\text { should be considered for when their regular medication fails. }\end{array}$ \\
\hline $\begin{array}{l}\text { Avoidance of patient } \\
\text { discouragement and } \\
\text { "Lapsed Consulters" }\end{array}$ & $\begin{array}{l}\text { Rigid adherence to a "step care across attacks" approach may result in ineffective recommendations initially. The patient may } \\
\text { withdraw from care and rely on "over the counter" medications. This may increase the risk of poor medication efficacy and } \\
\text { medication overuse. }\end{array}$ \\
\hline Medication cost & $\begin{array}{l}\text { Although cost is an important factor, less expensive but also less effective medications may result in increased indirect costs } \\
\text { (missed work, etc), and therefore greater overall costs. }\end{array}$ \\
\hline Opioid avoidance & $\begin{array}{l}\text { Opioid-containing analgesics are best avoided for acute migraine where possible. They are often no more effective than ASA / } \\
\text { NSAIDs }^{83} \text {, they are often overused }{ }^{153} \text {, and overuse often results in medication overuse headache. } .^{21,85}\end{array}$ \\
\hline $\begin{array}{l}\text { Avoidance of medication } \\
\text { overuse }\end{array}$ & $\begin{array}{l}\text { Relatively ineffective medications may result in more frequent medication use, and may result in medication overuse } \\
\text { headache. Opioid- and barbiturate-containing combination analgesics appear particularly problematic with regard to } \\
\text { medication overuse. }\end{array}$ \\
\hline
\end{tabular}


- Whether the pain builds up quickly and peaks early in the attack, or only later in the attack.

- Whether significant nausea occurs early in the attack where it may impede the effectiveness of oral medications, or only later in the attack.

- Whether the attack comes on during the day where it can be treated early, or is present in a fully developed form (often with nausea or early vomiting) upon awakening.

- The usual duration of the patient's attacks. Patients with attacks of long duration may be more prone to pain recurrence after initial acute treatment.

- Whether the patient has a migraine aura. This may allow for early treatment of the migraine attack, although for triptans there is evidence that treatment at pain onset is most effective (see later section, "Timing of triptan use in migraine with aura").

Many of these features are also considered in more detail in the individual treatment strategies discussed later in this document.

\section{Combined acute medication treatment approach}

1. Patients who present with severe attacks that often require bed rest should be given a triptan, with an anti-nauseant, if necessary, consistent with the stratified approach (see strategy 2b: Triptan strategy).

2. Patients whose attacks are usually less severe than those above, and who have not had adequate trials of non triptans can be considered for a "step care across attacks" approach as outlined below. They should be educated carefully about the options for acute migraine treatment and the treatment plan. Patient follow-up is important. For all acute medications, treatment early in the attack is generally more effective, but it is important that patients with frequent attacks avoid medication overuse.

i. Step 1: ASA 1,000 mg, ibuprofen $400 \mathrm{mg}$, diclofenac potassium $50 \mathrm{mg}$ or naproxen sodium 500 - $550 \mathrm{mg}$ (up to $825 \mathrm{mg}$ can be used). Acetaminophen $1,000 \mathrm{mg}$ can be used for patients intolerant of NSAIDs. For patients desiring a more rapid onset of action, solubilized ibuprofen, diclofenac potassium in a powdered formulation (for oral solution) or effervescent ASA can be used. Metoclopramide $10 \mathrm{mg}$ (or domperidone $10 \mathrm{mg}$ ) can be added if nausea is present. These may improve absorption, and therefore efficacy of the NSAID or acetaminophen (see strategy 1a: Acetaminophen strategy; Strategy 1b: NSAID strategy). For patients with relatively severe attacks in whom an NSAID is being tried, a triptan can also be prescribed at the same time as a rescue medication (see strategy 2a: NSAID with triptan rescue strategy). This strategy can also be used for patients who are found to generally respond well to their NSAID, but who do have treatment failure from time to time (for example, if they take their medication too late in their attack).

ii. Step 2: A triptan should be recommended as primary therapy, with the addition of an anti-nauseant (e.g., metoclopramide $10 \mathrm{mg}$ ), if necessary, for patients who do not respond well to NSAIDs or acetaminophen. Several different triptans should be tried in different attacks if the response to the first triptan is not excellent (see strategy 2b: triptan strategy). When a different triptan is tried, product monographs recommend that it not be used within 24 hours of the previous triptan.

iii.Step 3: For patients whose usual response to triptans remains inadequate in most attacks, or who sometimes respond well but have relatively frequent triptan failures, an NSAID (e.g., naproxen sodium 500 - $550 \mathrm{mg}$ ) should be given simultaneously with their triptan (see strategy $3 \mathrm{a}$ : triptan-NSAID combination strategy).

iv. Step 4: For patients with relatively severe attacks who usually respond well to their triptan-NSAID combination, the need for a further "rescue" medication should be considered for when the usual medication fails if the patient does not respond in every attack (see strategy $3 \mathrm{~b}$ : triptan-NSAID combination with rescue medication strategy).

v. Step 5: For patients who do not respond satisfactorily to either NSAIDs or triptans or combinations of these, the feasibility of using dihydroergotamine (DHE) either by nasal spray or if necessary by self-injection (subcutaneous or intramuscular) should be considered in the absence of contraindications. Concomitant use of an anti-nauseant (metoclopramide $10 \mathrm{mg}$ orally) should be considered, especially with DHE by injection (see strategy 3c: dihydroergotamine strategy).

vi. Step 6: Opioid analgesics (e.g., acetaminophen with tramadol or codeine) remain an option for patients without a satisfactory response to earlier treatment steps, but their frequency of use should be closely monitored and behavioural and pharmacological preventive treatment options should be explored. These medications are also an option for patients with contraindications to vasoconstrictor drugs and who do not respond to NSAIDs or non-opioid combination analgesics (see strategy 4: vasoconstrictor unresponsive-contraindicated strategy).

\section{EXPERT CONSENSUS}

i. Patients with severe attacks that often require bed rest: a. Should be given a triptan (with an anti-nauseant, if necessary), consistent with the stratified approach.

b. Subcutaneous sumatriptan $6 \mathrm{mg}$ may be the preferred triptan for severe attacks with early vomiting, or for severe attacks which do not respond to other triptan formulations.

ii. Patients with less severe attacks and who have not had adequate trials of non triptans:

a. Should be educated about acute treatment options. b. An anti-emetic (metoclopramide $10 \mathrm{mg}$ or domperidone $10 \mathrm{mg}$ ) can be added to acute migraine medications if needed for nausea.

c. A "step care across attacks" strategy as outlined below can be initiated with careful patient follow-up.

Step 1: ASA 1,000 mg, ibuprofen $400 \mathrm{mg}$, diclofenac potassium $50 \mathrm{mg}$, naproxen sodium $550 \mathrm{mg}$, or acetaminophen $1,000 \mathrm{mg}$ if NSAID intolerant. For patients with relatively severe attacks (but not usually requiring bed rest), a triptan can be 
prescribed at the same time. The triptan can be used as a rescue medication by the patient as necessary if the NSAID or acetaminophen occasionally fails, or can be adopted as the patient's primary acute migraine medication if the NSAID or acetaminophen proves unhelpful (see step 2 below).

Step 2: For patients not responding well to NSAIDs, use a triptan as the primary medication for acute migraine therapy:

a. At least three different triptans should be tried (in different attacks) if the response to the first triptan is not excellent. An excellent response is defined as pain free or almost pain free with the ability to resume usual activities at $2 \mathrm{~h}$ post-dose, and no significant side effects.

b. A triptan should be used to treat approximately three separate migraine attacks before being judged effective or ineffective.

c. Intranasal triptans which are partially absorbed through the nasal mucosa (e.g., zolmitriptan $5 \mathrm{mg}$ ) may be preferred to oral triptans for patients with nausea. It is important that patients administer them according to the product monograph to allow for maximum nasal drug absorption.

d. Orally dissolving tablets (wafers) may be the preferred oral triptan for patients with nausea exacerbated by taking fluids.

e. For patients with more than one migraine attack severity, providing medications from two different classes should be considered (e.g., a triptan and NSAID).

Step 3: For patients whose response to triptans remains inadequate because of incomplete relief or frequent treatment failure, an NSAID (e.g., naproxen sodium 500 - $550 \mathrm{mg}$ ) should be used simultaneously with their triptan.

Step 4: For patients with a good response to their triptanNSAID combination therapy but who experience occasional treatment failure, consider the need for a rescue medication. Rescue medications can include additional NSAIDs (oral, rectal, or injectable with oral metoclopramide), prochlorperazine (oral, rectal), corticosteroids, and acetaminophen with tramadol or codeine (not for routine use; monitor frequency of use carefully).

Step 5: For patients who do not respond satisfactorily to an NSAID-triptan combination, the use of dihydroergotamine (nasal spray or self-injection), combined with oral meto-clopramide (if needed), can be considered.

Step 6: Although not recommended for routine use in migraine, opioid analgesics (e.g., acetaminophen with codeine or tramadol) remain an option for patients without a satisfactory response to earlier treatment steps, but:

a. their frequency of use should be closely monitored (using a headache diary).

b. behavioural and pharmacological preventive treatment options should be explored.

$c$. these medications are also a treatment option for patients with contraindications to vasoconstrictor drugs and who do not respond to NSAIDs.

\section{Acute Migraine Treatment Strategies}

There are many drugs available for acute migraine treatment. These need to be chosen based upon patient clinical characteristics, and each needs to be used appropriately. The medications are organized here into a number of treatment strategies, and are discussed below. Once the clinical data on a specific patient has been gathered, including past medication use and response, an appropriate strategy should be chosen and implemented. Depending upon the patient's response to the chosen pharmacological treatment strategy, the same strategy can be continued, or a new strategy can be implemented.

The primary drugs for acute migraine attack treatment are the NSAIDs (including ASA) and the triptans. Acetaminophen is widely used, but is considered less effective than the NSAIDs, and suitable mainly for attacks of mild to moderate severity. In the treatment strategies discussed below, metoclopramide is recommended when an anti-nauseant is needed, as more evidence is available for efficacy for this drug than for the related medication, domperidone. Domperidone can also be used, and may have fewer side effects; however, domperidone may be associated with QT prolongation in some patients.

\section{Mild to moderate attack strategies}

For patients with attacks that are not disabling (i.e., attacks do not require bed rest, and do not stop participation in activities, although it may be somewhat difficult for the patient to continue), the following two strategies may be most appropriate:

\section{a. Acetaminophen strategy}

This strategy simply involves the use of acetaminophen 1,000 $\mathrm{mg}$, as needed. It can be used alone, or in combination with metoclopramide $10 \mathrm{mg}$ (or domperidone $10 \mathrm{mg}$ ). Acetaminophen has the advantage of fewer gastrointestinal side effects than NSAIDs, and has been shown to be superior to placebo in the acute treatment of migraine attacks., ${ }^{2,3}$ Acetaminophen is considered to be less effective than NSAIDs for acute migraine treatment; and there is some limited randomized controlled data to support this in pediatric patients ${ }^{4}$, and in adults. ${ }^{5}$

Acetaminophen is thought to act primarily centrally, and inhibits prostaglandin synthesis is neurons. Because it is unable to inhibit prostaglandin synthesis in leukocytes and platelets, it does not have anti-inflammatory or anti-platelet activity. Acetaminophen-induced analgesia is blocked by CB1 receptor antagonists, suggesting that it also acts through cannabinoid receptors. ${ }^{6}$ It has a relatively short elimination half-life of $2-3 \mathrm{~h}$, so repeated dosing may be necessary for a sustained analgesic effect. Maximum plasma concentrations of acetaminophen are reached within 30 - 60 minutes. The usual recommended dose for analgesia is $650-1,000 \mathrm{mg}$ (a dose of $1,000 \mathrm{mg}$ is recommended for migraine). This can be repeated every four to six hours, with a maximum of $4,000 \mathrm{mg}$ per 24 hours.

\section{EXPERT CONSENSUS}

$i$. Acetaminophen is an effective option for acute migraine therapy for some patients with attacks of mild to moderate intensity.

\section{b. NSAID strategy}

A number of commonly used NSAIDs have high quality evidence for efficacy for acute migraine treatment. These include ASA, ibuprofen, naproxen sodium, and diclofenac potassium. 
Table 4: Non-Steroidal Anti-Inflammatory Drugs: Pharmacokinetics and Dosage

\begin{tabular}{|c|c|c|c|c|}
\hline Drug & $\mathbf{T}_{\max }$ (hours) & $\begin{array}{l}\text { Elimination half- } \\
\text { life (hours) }\end{array}$ & Dose (mg)* & $\begin{array}{l}\text { Dosage interval (if repeated) } \\
\& \text { maximum daily dose* }\end{array}$ \\
\hline $\begin{array}{l}\text { Acetylsalicylic acid } \\
\text { (ASA) (tablet) }\end{array}$ & $1-2$ & $\begin{array}{c}\text { ASA: } 0.25 \\
\text { Salicylate (active): } \\
\text { 5-6 (after } 1 \mathrm{~g} \text { dose) }\end{array}$ & $975-1,000$ & $\begin{array}{l}\text { every } 4-6 \mathrm{~h} \text {; } \\
\text { max: } 5.4 \mathrm{~g} \text { /day (varies depending on indication) }\end{array}$ \\
\hline $\begin{array}{l}\text { Acetylsalicylic acid } \\
\text { (ASA)(effervescent) }\end{array}$ & $\sim 20$ min & as above & $975-1,000$ & $\begin{array}{l}\text { every } 4 \mathrm{~h} ; \\
\text { max: } 8(325 \mathrm{mg}) \text { tablets }\end{array}$ \\
\hline Ibuprofen (tablet) & $1-2$ & 2 & 400 & $\begin{array}{l}\text { every } 4 \mathrm{~h} ; \\
\max : 2,400 \mathrm{mg}\end{array}$ \\
\hline Ibuprofen (solubilized) & $<1$ & 2 & 400 & $\begin{array}{l}\text { every } 4 \mathrm{~h} ; \\
\text { max: } 2,400 \mathrm{mg}\end{array}$ \\
\hline Naproxen sodium $* *$ & 2 & 14 & $\begin{array}{l}500-550 \text { (up } \\
\text { to } 825 \mathrm{mg} \text { ) }\end{array}$ & $\begin{array}{l}\text { twice a day; } \\
\text { max: } 1,375 \mathrm{mg}\end{array}$ \\
\hline $\begin{array}{l}\text { Diclofenac potassium } \\
\text { (tablet) }\end{array}$ & $<1$ & 2 & 50 & $\begin{array}{l}\text { 3-4 times a day; } \\
\max : 150 \mathrm{mg}\end{array}$ \\
\hline $\begin{array}{l}\text { Diclofenac potassium } \\
\text { (powder for oral solution) }\end{array}$ & $15 \mathrm{~min}$ & 2 & 50 & single dose recommended for migraine attack \\
\hline Ketorolac (tablet)*** & $<1$ & 5 & 10 & 3-4 times a day; max: $40 \mathrm{mg}$ \\
\hline
\end{tabular}

Tmax = time to maximum plasma concentration; *Note: for acute migraine treatment, only one or two doses are usually recommended; doses are for adults; **Absorbed more quickly than naproxen; ***No controlled trial evidence for efficacy in migraine

Other NSAIDs (e.g., oral ketorolac) lack randomized controlled trial studies in migraine. It would appear most prudent to utilize NSAIDs with good evidence for efficacy, although it is possible that other NSAIDs might be more effective in selected patients. The NSAID can be used alone or with metoclopramide.

In choosing an NSAID, the pharmacokinetic properties of the drug should be considered. Rapid absorption provides the opportunity for a rapid onset of action for quick migraine relief, and this may be important for patients with migraine attacks that increase rapidly in intensity. For patients with relatively prolonged migraine attacks, an NSAID with a longer half-life (e.g., naproxen) may reduce the likelihood of headache recurrence. NSAIDs currently used for migraine have quite different pharmacokinetic properties (Table 4).

Rapidity of absorption of NSAIDs does depend in part on tablet dissolution times, and solubilized formulations of ibuprofen, effervescent ASA, and diclofenac potassium powder for oral solution may be especially useful because of more rapid oral absorption (see Table 4).
There is probably no ideal NSAID for migraine, and it is often worthwhile for patients to try several if their response to their initial NSAID is not ideal. Numbers needed to treat (NNTs) for various NSAIDs (the number of patients who will need to be treated to achieve a pain relief endpoint in one patient over and above the placebo response) as available are given in Table 5.

Ibuprofen appears to be the most commonly used NSAID for migraine in Canada, perhaps in part because it is widely available without prescription. ${ }^{7}$ Its relatively short elimination half-life $(2 \mathrm{~h})$ may result in the need for repeated dosing in many patients. Ibuprofen is preferred by many patients, perhaps because of its rapid onset of action. It may produce less gastric irritation than ASA, and the NNT for a positive response as compared to placebo is at least as good if not better than for ASA in migraine. In controlled clinical trials, doses greater than 400 $\mathrm{mg}$ were no more effective than the $400 \mathrm{mg}$ dose for acute migraine attacks.

Ibuprofen has shown good efficacy in acute migraine ${ }^{8,9}$, and appears to have similar efficacy compared to other acute

Table 5:Number needed to treat (NNT) for simple analgesics/NSAIDs in the acute treatment of

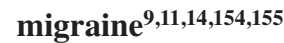

\begin{tabular}{l|l|l}
\hline Analgesic or NSAID (tablets) & NNT (2-h headache relief) & NNT (2-h pain-free) \\
\hline Acetaminophen $1,000 \mathrm{mg}^{154}$ & 5.0 & 12.0 \\
\hline ASA $900-1,000 \mathrm{mg}^{14}$ & 4.9 & 8.1 \\
\hline ASA $900 \mathrm{mg}+{\mathrm{metoclopramide} 10 \mathrm{mg}^{14}}^{14}$ & 3.3 & 8.8 \\
\hline Ibuprofen $400 \mathrm{mg}^{9}$ & 3.2 & 7.2 \\
\hline Naproxen sodium $500-825 \mathrm{mg}^{11}$ & 7.0 & 15.0 \\
\hline Diclofenac potassium (tablet) & 6.2 & 8.9 \\
\hline Diclofenac potassium powder for oral solution ${ }^{13,155}$ & 4.5 & 7.1 \\
\hline
\end{tabular}


migraine drugs. In one large, double-blind, cross-over trial, the percentage of patients with a reduction in headache severity from moderate or severe to mild or no pain at $2 \mathrm{~h}$ (primary endpoint) was $52.5 \%$ for effervescent ASA $1,000 \mathrm{mg}, 60.2 \%$ for ibuprofen tablets $400 \mathrm{mg}, 55.8 \%$ for sumatriptan $50 \mathrm{mg}$, and $30.6 \%$ for placebo. All active treatments were superior to placebo $(\mathrm{p}<$ $0.0001)$, whereas the active treatments were not statistically different from one another. ${ }^{10}$ Ibuprofen is, therefore, a wellestablished acute migraine headache treatment. Its strengths include a short time to maximal plasma concentrations and a rapid onset of action, with the solubilized formulation being somewhat faster than the regular tablets. Its main shortcoming is its relatively short half-life. When repeated dosing is necessary, the patient may respond better to an NSAID with a longer duration of action (e.g., naproxen sodium).

Naproxen sodium also has good evidence for efficacy in migraine $^{11}$, and is widely used. Naproxen sodium (immediate release formulation) is preferred to naproxen due to its faster onset of action, and there is some evidence (one clinical trial) that the $825 \mathrm{mg}$ dose is more effective than the $500 \mathrm{mg}$ dose. ${ }^{11}$ Naproxen sodium may be used up to twice daily, if necessary, and its long half-life may be an advantage over other NSAIDs in some patients.

There is good evidence supporting the use of diclofenac potassium for the acute treatment of migraine. ${ }^{12}$ As the sodium salt of diclofenac is only available in Canada as enteric-coated or sustained release tablets, diclofenac potassium should be used in migraine because of a faster onset of action. Although doses greater than $50 \mathrm{mg}$ (i.e., $100 \mathrm{mg}$ ) have not been shown to be superior to the $50 \mathrm{mg}$ dose, it is possible that higher doses may benefit individual patients. Diclofenac potassium has recently become available as a powder $(50 \mathrm{mg})$ for oral solution. It has a $\mathrm{T}_{\max }$ of 15 minutes, and has shown superiority over the regular tablet at the same dose for the pain-free at two hours endpoint in one study $(p=0.0035) .{ }^{13}$ The plasma half-life for diclofenac potassium is relatively short and similar to that of ibuprofen.

ASA in doses of 975 to $1,000 \mathrm{mg}$ with or without metoclopramide also has good evidence for efficacy in acute migraine; addition of metoclopramide $10 \mathrm{mg}$ improves relief of nausea. ${ }^{14}$ Effervescent ASA has a faster onset of action than regular tablets (Table 4), and has shown similar efficacy to sumatriptan $50 \mathrm{mg}$ for the treatment of acute migraine attacks (including severe attacks). ${ }^{15}$

\section{EXPERT CONSENSUS}

i. NSAIDs (including ASA) are helpful for many patients with migraine. Although it cannot be predicted which NSAID will be best for a specific patient, pharmacokinetic differences between them should be considered when treatment recommendations are made.

ii. For patients with migraine attacks that increase in intensity rapidly, diclofenac potassium powder for oral solution, effervescent ASA, and solubilized ibuprofen capsules have a rapid onset of action and may be particularly helpful.

iii.For patients with migraine attacks that increase in intensity rapidly, diclofenac potassium tablets have the most rapid onset of action for tablet formulations of NSAIDs (note: diclofenac potassium powder for oral solution has a more rapid oral absorption than tablets). $i v$. The long plasma half-life of naproxen sodium may make it particularly helpful for patients with prolonged migraine attacks.

\section{Moderate-severe attack or NSAID failure strategies}

\section{a. NSAID with triptan rescue strategy}

Clinical trials indicate that NSAIDs may be helpful for patients with migraine of any severity, although many of the NSAID clinical trials excluded patients who frequently required bed rest for their attacks. For the patient with relatively severe migraine attacks, when an NSAID is tried, it may be useful to provide a triptan as a rescue medication, should the NSAID prove unsatisfactory. The triptan in this "step-care within attack" mode of use may also not prove entirely satisfactory as it will be taken relatively late in the attack, but nevertheless it should give the patient some relief, and perhaps help avoid the patient becoming a "lapsed consulter". Patients can then decide over time whether it is necessary to make the triptan their primary acute medication rather than the NSAID, in which case they can start to take it early in the attack.

Another situation where the "NSAID with triptan rescue" strategy can be useful is if the patient's attacks usually do respond well to an NSAID, but the NSAID occasionally fails. The patient will then use the triptan for only a relatively small proportion of attacks. If patients have attacks of varying severity and are able to predict the eventual intensity of a developing migraine attack, they may choose to take a triptan early only for those attacks that they think will become severe, and an NSAID for those that will likely be of mild or moderate intensity. If they are unable to predict the intensity of the developing migraine attack, the "NSAID with triptan rescue" strategy may be more satisfactory for them.

More details on triptan use are provided in the next section below.

\section{b. Triptan strategy}

This section will provide a detailed description of triptan pharmacology and adverse events, as the triptans are very important acute migraine medications and many physicians are not as familiar with them as they are with NSAIDs. Clinical use of the triptan strategy will then be summarized. Triptans can be used with or without metoclopramide.

\section{Triptan pharmacology}

Triptans are serotonin agonists with high affinity for $5-\mathrm{HT}_{1 \mathrm{~B}}$ and $5-\mathrm{HT}_{1 \mathrm{D}}$ receptors, and act on the trigeminovascular system. Through activation of the $5-\mathrm{HT}_{1 \mathrm{D}}$ receptor, they may block the release of vasoactive peptides from perivascular trigeminal nociceptive nerve terminals, and also inhibit synaptic transmission from primary to secondary sensory neurons in the trigeminocervical complex. Selective vasoconstrictor effects on intracranial blood vessels through activation of 5- $\mathrm{HT}_{1 \mathrm{~B}}$ receptors on vascular smooth muscle also may be important in their migraine-abortive efficacy. Triptans may also facilitate descending pain inhibitory systems. ${ }^{16,17}$ Almotriptan is also an agonist at the 5- $\mathrm{HT}_{1 \mathrm{~F}}$ receptor (shown to be effective in aborting migraine) ${ }^{18}$, and frovatriptan at the $5-\mathrm{HT}_{7}$ receptor (clinical 
relevance unknown). Triptans not only relieve migraine pain, and but also relieve associated symptoms including nausea, vomiting, photophobia, and phonophobia.

A major advantage of triptans over most other alternatives (e.g., ergots, analgesics) is their more specific mechanism of action and favourable side effect profile. However, it is estimated that up to one-third of patients fail to achieve adequate pain relief with oral triptans. ${ }^{17,19}$

\section{Triptans and treatment early in the attack}

Although triptans can be effective at any time during a migraine attack, their efficacy is better when they are taken early in an attack (when headache pain is still mild) ${ }^{20}$ However, early intake can lead to frequent medication use and medication overuse headache in some patients. In epidemiological studies, the risk for migraine chronification became significant with triptan intake at 12 days per month. ${ }^{21}$

\section{Triptan formulations}

Seven triptans are currently available in Canada: almotriptan, eletriptan, frovatriptan, naratriptan, rizatriptan, sumatriptan, and zolmitriptan. All are available in oral dosage forms, two as intranasal sprays (sumatriptan, zolmitriptan), and one as a subcutaneous (SC) injection (sumatriptan). Rizatriptan and zolmitriptan are also available as orally dissolving tablets (wafers).

The route of administration of a triptan can affect its efficacy, tolerability, and speed of onset. Injections (SC) and nasal sprays generally have a faster onset of action and higher efficacy compared to orally administered medications. Subcutaneous sumatriptan $(6 \mathrm{mg})$ has the highest response rates; up to $80 \%$ of patients have pain relief after $2 \mathrm{~h} .{ }^{22,23}$ It has a therapeutic gain of 51 percentage points $(70 \%$ response with active treatment vs. $19 \%$ with placebo), which is the largest for all available triptans. ${ }^{24}$ However, oral tablets are often preferred by patients even though they have a slower onset of action. The oral route may not be feasible in the presence of significant nausea and/or

Table 6: Triptans - pharmacokinetics ${ }^{19,23,29,31,156,157}$

\begin{tabular}{|c|c|c|c|c|c|c|c|}
\hline & Almotriptan & Eletriptan & Frovatriptan & Naratriptan & Rizatriptan & Sumatriptan & Zolmitriptan \\
\hline Bioavailability & $70 \%$ & $50 \%$ & $\begin{array}{l}\text { Males:20\% } \\
\text { Females: } 30 \%\end{array}$ & $\begin{array}{l}\text { Males: } 63 \% \\
\text { Females: } 74 \%\end{array}$ & $45 \%$ & $\begin{array}{l}\text { SC: } 96 \% \\
\text { Oral: } 14 \% \\
\text { Nasal: } 16 \%\end{array}$ & $\begin{array}{l}\text { Oral: } 40 \% \\
\text { Nasal: } 41 \%\end{array}$ \\
\hline $\mathbf{T}_{\max }$ & $1-3 h$ & $1-2 \mathrm{~h}$ & $2-4 h$ & $2-3 h$ & $\begin{array}{l}\text { Oral: } \\
1-1.5 \mathrm{~h} \\
\text { ODT: } 1.6- \\
2.5 \mathrm{~h}\end{array}$ & $\begin{array}{l}\text { SC: } 15 \mathrm{~min} \\
\text { Oral: } 2.5 \mathrm{~h} \\
\text { Nasal: } \\
1-1.5 \mathrm{~h}\end{array}$ & $\begin{array}{l}\text { Oral/ODT: } \\
2 \mathrm{~h} \\
\text { Nasal: } 2 \mathrm{~h}\end{array}$ \\
\hline Onset & $0.5-2 \mathrm{~h}$ & $0.5-1 \mathrm{~h}$ & $\begin{array}{l}\text { precise data not } \\
\text { available; slow } \\
\text { onset for most } \\
\text { patients }\end{array}$ & $1-3 h$ & $0.5-1 \mathrm{~h}$ & $\begin{array}{l}\text { SC: } \\
10-15 \text { min } \\
\text { Oral (fast } \\
\text { dissolving): } 30 \\
\text { min. Nasal: } \\
15 \text { min }\end{array}$ & $\begin{array}{l}\text { Oral/ODT: } \\
45 \text { min } \\
\text { Nasal: } 10-15 \\
\text { min }\end{array}$ \\
\hline $\begin{array}{l}\text { Elimination } \\
\text { half-life }\end{array}$ & $3-4 h$ & $3.8 \mathrm{~h}$ & $\sim 26 \mathrm{~h}$ & $5-8 h$ & $2-3 h$ & $2 \mathrm{~h}$ & $2.5-3 \mathrm{~h}$ \\
\hline $\begin{array}{l}\text { Metabolism \& } \\
\text { elimination }\end{array}$ & $\begin{array}{l}\text { MAO-A, } \\
\text { CYP3A4, } \\
\text { CYP2D6; inactive } \\
\text { metabolites; } 40 \% \\
\text { unchanged in } \\
\text { urine }\end{array}$ & $\begin{array}{l}\text { CYP3A4; } \\
\text { active N- } \\
\text { demethylated } \\
\text { metabolite; } \\
\text { 90\% non-renal } \\
\text { clearance }\end{array}$ & $\begin{array}{l}\text { CYP1A2; several } \\
\text { metabolites; active } \\
\text { desmethyl } \\
\text { frovatriptan }\end{array}$ & $\begin{array}{l}\text { CYP } 450 \\
\text { (various } \\
\text { isoenzymes); } \\
\text { inactive } \\
\text { metabolites; } \\
50 \% \text { unchanged } \\
\text { in urine }\end{array}$ & $\begin{array}{l}\text { MAO-A; } \\
\text { inactive \& } \\
\text { one active } \\
\text { metabolites; } \\
8-16 \% \\
\text { unchanged in } \\
\text { urine }\end{array}$ & $\begin{array}{l}\text { MAO-A; } \\
\text { inactive } \\
\text { metabolites }\end{array}$ & $\begin{array}{l}\text { CYP1A2, } \\
\text { MAO-A; } \\
\text { inactive \& one } \\
\text { active } \\
\text { metabolites; } 8 \% \\
\text { unchanged in } \\
\text { urine }\end{array}$ \\
\hline $\begin{array}{l}\text { Significant drug } \\
\text { interactions* }\end{array}$ & None & $\begin{array}{l}\text { CYP 3A4 } \\
\text { inhibitors: E } \\
\text { contraindicated } \\
\text { within } 72 \text { h of } \\
\text { potent } \\
\text { CYP3A4 } \\
\text { inhibitors (e.g., } \\
\text { ketoconazole, } \\
\text { itraconazole) }\end{array}$ & $\begin{array}{l}\text { None (CYP1A2 } \\
\text { inhibitors have } \\
\text { minimal potential } \\
\text { to affect kinetics } \\
\text { of frovatriptan) }\end{array}$ & None & $\begin{array}{l}\text { MAOIs } \\
\text { (avoid use } \\
\text { within } 14 \\
\text { days) } \\
\text { Propranolol } \\
\text { ( } \uparrow \text { AUC of } \\
\text { R.; max. } \\
5 \mathrm{mg} \text { single } \\
\text { doses \& } \\
10 \mathrm{mg} / 24 \mathrm{~h} \\
\text { of } \mathrm{R} \text { ) }\end{array}$ & $\begin{array}{l}\text { MAOIs (avoid } \\
\text { use within } 14 \\
\text { days) }\end{array}$ & $\begin{array}{l}\text { MAOIs (avoid } \\
\text { use within } 14 \\
\text { days) } \\
\text { CYP 1A2 } \\
\text { inhibitors (e.g., } \\
\text { cimetidine, } \\
\text { fluvoxamine, } \\
\text { ciprofloxacin); } \\
\uparrow \text { AUC \& } \mathrm{t}_{1 / 2} \text { of } \\
\mathrm{Z} ; \max . \\
5 \mathrm{mg} / 24 \mathrm{~h} \text { of } \mathrm{Z} \text { ) }\end{array}$ \\
\hline
\end{tabular}

*All triptans: do not use within 24 hours of an ergot derivative (e.g., ergotamine, DHE) or another triptan (due to possibility of additive vasoconstriction); there is a theoretical possibility of serotonin syndrome (rare) when combined with other serotonergic drugs (e.g., SSRIs, lithium) - however, this is controversial; AUC = area under the curve; MAOI = monoamine oxidase inhibitor; $\mathrm{E}=$ eletriptan; $\mathrm{R}=$ rizatriptan; $\mathrm{Z}=$ zolmitriptan; $\mathrm{ODT}=$ orally disintegrating tablet 
vomiting. Patients may need access to more than one triptan formulation, based on attack characteristics. ${ }^{25,26}$

\section{Triptan choice and patient preference}

Although the triptans are chemically related drugs, in clinical practice it is a common experience that some patients will prefer one triptan to another. This may relate to a perceived difference in efficacy, differences in the side effects experienced, or both. Which triptan a patient will prefer cannot be predicted. It is generally accepted that the differences between patients are greater than the differences between triptans, and no one triptan is superior to the others for all patients. With regard to individual patients this has led to the adage that the best triptan "is the one that works best for the patient". The different triptans do have different pharmacokinetic properties, and also to some extent show differences in side effects. Triptan choice can therefore be tailored to some extent to the individual patient. Rapidity of pain relief, the probability of pain relief, the probability of headache recurrence, and the probability of adverse events all are potential contributors to how satisfactory the patient's response will be to any given triptan. ${ }^{17,27,28}$

\section{Pharmacokinetic differences among triptans and onset of pain relief}

The pharmacokinetic differences among the triptans (Table 6) may be clinically relevant for individual patients. ${ }^{19,23,28,29}$ Subcutaneous sumatriptan has the most rapid onset of action (approximately $10 \mathrm{~min}$ ) compared to oral or intranasal triptans. ${ }^{30}$ Intranasal zolmitriptan also has a relatively rapid onset of action $(10-15 \mathrm{~min}){ }^{29,31}$ Of the oral triptans, rizatriptan and eletriptan have a relatively fast onset of action (approximately $30 \mathrm{~min}$ ). Naratriptan and frovatriptan have the slowest onset of action (up to $4 \mathrm{~h}$ ). There is no evidence that orally dissolving tablets/wafers act more quickly than regular tablets.

Subcutaneous sumatriptan with its rapid absorption and onset of action, coupled with no interference with absorption due to nausea or vomiting, gives it a unique therapeutic role. Although it is not as widely used as the oral triptans because of the need for an injection and also because of increased side effects, it should be considered where other formulations have proven less effective than desired, or where early vomiting in the attack renders other formulations ineffective.

Among the oral tablets, frovatriptan and naratriptan stand out as having a slower absorption, and a longer time to $\mathrm{T}_{\max }$. The remaining triptans show less differentiation, with rizatriptan having perhaps the fastest time to $\mathrm{T}_{\max }$, indicating the potential for a rapid onset of action.

\section{The probability of pain relief}

Table 7 shows the number needed to treat (NNT) for the "pain free at two hours" endpoint. This is the number of patients that need to be treated to render one patient pain free at two hours over and above the placebo response. Subcutaneous sumatriptan (6 mg) has the lowest NNT, indication the best efficacy for this endpoint. Among the oral triptans, rizatriptan provides the lowest NNT.
Table 7: Triptans - Number Needed to Treat (NNT) for painfree response at $2 \mathrm{~h}$ in migraine*31,158-162

\begin{tabular}{l|l|l}
\hline \multicolumn{1}{c|}{ Drug and dosage } & \multicolumn{1}{c|}{ Route } & \multicolumn{1}{c}{$\begin{array}{c}\text { NNT (for 2-h pain-free } \\
\text { vs. placebo)** }\end{array}$} \\
\hline Sumatriptan $6 \mathrm{mg}$ & subcutaneous & $2.3^{158}$ \\
\hline Sumatriptan $20 \mathrm{mg}$ & intranasal & $4.7^{159}$ \\
\hline Zolmitriptan $5 \mathrm{mg}$ & intranasal & $4.6^{31}$ \\
\hline Almotriptan 12.5 & oral & $4.3^{160}$ \\
\hline Eletriptan $20 \mathrm{mg}$ & oral & 10 \\
\hline Eletriptan $40 \mathrm{mg}$ & oral & 4.5 \\
\hline Frovatriptan $2.5 \mathrm{mg}$ & oral & $8.5^{161}$ \\
\hline Naratriptan $2.5 \mathrm{mg}$ & oral & 8.2 \\
\hline Rizatriptan $10 \mathrm{mg}$ & oral & 3.1 \\
\hline Sumatriptan $50 \mathrm{mg}$ & oral & $6.1^{162}$ \\
\hline Sumatriptan $100 \mathrm{mg}$ & oral & $4.7^{162}$ \\
\hline Zolmitriptan $2.5 \mathrm{mg}$ & oral & 5.9 \\
\hline
\end{tabular}

* Adapted from: Bandolier (http://www.medicine.ox.ac.uk/bandolier) except as noted; ** Note: Migraine attacks were treated at moderate or severe intensity. NNTs may be lower for individual drugs when treatment is taken early in the migraine attack.

\section{Adverse events}

Adverse events also vary greatly from patient to patient, with one patient tolerating one triptan much better than another, while a second patient may show the reverse. Although the differences between the oral triptans are not large, almotriptan appears to have the lowest absolute adverse event rate. ${ }^{32}$ Triptan safety during pregnancy and lactation has not been established, but available information on triptan use during pregnancy and lactation is discussed below under the "Migraine during pregnancy strategy" and the "Migraine during lactation strategy".

\section{a) Cardiovascular safety}

Concerns about the cardiovascular safety of triptans are due, in part, to adverse effects experienced by some patients, which are referred to as "triptan sensations". These effects, including burning, tingling or tightness in the face, neck, limbs or chest, have been reported in approximately $1-7 \%$ of patients in clinical trials. Triptan-associated chest symptoms are generally mild and transient, and are not associated with electrocardiographic or enzymatic evidence of myocardial ischemia. However, because $5-\mathrm{HT}_{1 \mathrm{~B}}$ receptors are located on coronary arteries, triptans can constrict coronary arteries to a small extent, which is insignificant in patients without underlying coronary artery disease. Triptans do not appear to differ from one another in this regard. ${ }^{23}$ The Triptan Cardiovascular Safety Expert Panel, a multidisciplinary panel convened by the American Headache Society, concluded that while serious cardiovascular adverse events have occurred after the use of triptans, the frequency in both clinical trials and in clinical practice appeared to be very low (less than one per one million exposed). ${ }^{33}$ All triptans exhibit a similar safety profile when prescribed appropriately. 
Triptans are contraindicated in patients with ischemic heart disease, coronary vasospasm, previous myocardial infarction, cardiac arrhythmias, cerebral or peripheral vascular disease, or uncontrolled or severe hypertension; they should be used with caution in hemiplegic migraine.

\section{b) Serotonin syndrome}

Migraine and depression are common, co-morbid, chronic illnesses. ${ }^{34,35}$ Triptans and SSRIs (selective serotonin reuptake inhibitors)/SNRIs (serotonin/norepinephrine reuptake inhibitors) have been taken in combination by millions of patients without resulting serotonin syndrome. ${ }^{36}$ In July 2006, the United States (U.S.) Food and Drug Administration (FDA) issued an alert regarding the potential for life-threatening serotonin syndrome in patients taking triptans concomitantly with SSRIs or SNRIs, based on 29 case reports of serotonin syndrome. The FDA recommended that patients receiving these drugs concomitantly be informed of the possible risk of serotonin syndrome.

The American Headache Society (AHS) has issued a position paper regarding the FDA alert on the use of triptans combined with SSRIs/SNRIs.$^{37}$ Using the Sternbach Criteria for Serotonin Syndrome or the Hunter Serotonin Toxicity Criteria, the AHS assessed the 29 cases in the FDA report, as well as a more recently published review of 11 cases of serotonin syndrome resulting from triptan monotherapy. ${ }^{38}$ Of the 29 cases obtained from the FDA, only 10 cases met the Sternbach Criteria for diagnosing serotonin syndrome, and none met the Hunter Criteria. Case reports of serotonin syndrome involving triptan monotherapy do not have sufficient details to confirm the diagnosis. The AHS concluded that inadequate data are available to determine the risk of serotonin syndrome with combined use of a triptan and SSRI/SNRI, or with triptan monotherapy. Furthermore, the currently available evidence does not support limiting the use of triptans with SSRIs/SNRIs, or the use of triptan monotherapy, due to concerns of serotonin syndrome. Patients taking both a triptan and an SSRI/SNRI should be informed of the symptoms of serotonin syndrome (although rare), and instructed to inform their physician immediately should such symptoms occur, in order to ensure prompt treatment. ${ }^{37}$ Symptoms of serotonin syndrome include tachycardia, muscle twitching, tremor, sweating, and agitation.

\section{The triptan strategy and overall triptan choice}

This section will summarize several aspects of triptan use. For more information on headache recurrence and headache persistence after triptan use, please see specific sections below which deal with these issues. Table 8 shows the triptans available in Canada, and the doses usually used.

\section{Treatment early in the attack}

Like all acute migraine medications, triptans are more effective if taken early in the migraine attack (see a later section "The timing of triptan use in migraine with aura" for more information on migraine with aura). Patients should be advised to take them early in migraine without aura if they anticipate a migraine attack of at least moderate severity. For patients with relatively frequent migraine attacks this advice may need to be tempered with a caution that when triptans are taken on ten days a month or more (triptan overuse), patients may be at risk for more frequent headache attacks (triptan overuse headache). ${ }^{39}$

\section{Choosing a triptan formulation}

The response of an individual patient to a specific triptan cannot be predicted with accuracy, but some attempt can be made to tailor the triptan to the patient's needs. This requires an adequate headache history, and information about how quickly the patient's attacks build up in intensity and how disabling the attacks are may be helpful. In general, for the oral triptans, if speed of onset and a high response rate are considered important by the patient, rizatriptan and eletriptan would be good choices overall. If headache recurrence is an issue, eletriptan and frovatriptan could have an advantage. If side effects are an issue, almotriptan would appear to have an advantage, and still couples this advantage with a good response rate and good headache recurrence profile. ${ }^{32}$

If nausea is present, the nasal sprays can be useful, particularly zolmitriptan $5 \mathrm{mg}$ which shows significant nasal drug absorption, and a rapid onset of action. ${ }^{40,41}$ If nausea is milder but exacerbated by taking liquids, the two oral wafers, rizatriptan and zolmitriptan, can be useful. They are not absorbed through the oral mucosa, and are therefore basically

Table 8: Triptan formulations available in Canada, with doses most commonly used*

\begin{tabular}{l|c|c|c|c}
\hline \multirow{2}{*}{ Medication } & \multicolumn{4}{|c}{ Formulation and dose (mg) } \\
\cline { 2 - 5 } & Tablet & Wafer** & Nasal spray & Injection \\
\hline Sumatriptan & 50,100 & 2.5 & 5 & 6 \\
\hline Zolmitriptan & 2.5 & 10 & & \\
\hline Rizatriptan & 10 & & & \\
\hline Naratriptan & 2.5 & & & \\
\hline Eletriptan & 40 & & & \\
\hline Almotriptan & 12.5 & & & \\
\hline Frovatriptan & 2.5 & & & \\
\hline
\end{tabular}

*See Table 9 for more detailed information regarding clinical use; **Orally disintegrating tablet 
equivalent to the corresponding oral tablets except that water is not required for ingestion. ${ }^{42}$

Sumatriptan $(6 \mathrm{mg})$ by $\mathrm{SC}$ self-injection remains the triptan formulation with the highest overall headache response rate, and is the only formulation which guarantees complete absorption of the administered dose in the presence of vomiting. It also produces peak serum levels more rapidly than the other triptan formulations. It should be considered when patients awaken with fully developed migraine attacks that do not respond to oral triptans, when patients vomit early in the attack, or in general when migraine attacks do not respond well to other triptan formulations. Zolmitriptan nasal spray can also be considered in these situations, particularly in patients who are reluctant to use an injectable formulation. The triptan formulations available in Canada are shown in Table 8. Because individual patients respond differently in an unpredictable fashion, patients should if necessary try several other triptans over time, if the response to their current triptan is not optimal.

Patients with a history of sulfonamide (sulfa) allergies usually tolerate triptans well, including those that contain a sulfonamide moiety or sulfonyl group. If previous reactions to sulfa drugs have been severe, there is the option of choosing triptans without a sulfonamide or sulfonyl group in their chemical structure. Zolmitriptan, rizatriptan, and frovatriptan do not have a sulfonamide moiety or sulfonyl group, whereas almotriptan and eletriptan both have a sulfonyl group, and naratriptan and sumatriptan have a sulphonamide moiety.

\section{Triptan use with an anti-emetic}

Although the triptans will often treat associated symptoms like nausea quite satisfactorily at the same time as they relieve the headache, there are two situations where the addition of an anti-emetic (metoclopramide or domperidone), to be taken simultaneously with the triptan, can be helpful. The first is if nausea is so pronounced that additional medication is required to control this symptom. The second is if the response to the triptan is not fully satisfactory, perhaps because of gastric stasis and delayed absorption of the triptan. It has been demonstrated that migraineurs suffer from gastric stasis during an acute migraine attack, and also interictally between migraine attacks. ${ }^{43,44}$

Although parenteral metoclopramide is used to treat the headache component of the migraine attack in the emergency department, metoclopramide in oral form seems much less effective for that purpose, and is used primarily to treat migrainerelated nausea and to improve gastric motility. Either metoclopramide or domperidone can be used. Metoclopramide is used much more widely in migraine, and has more evidence for efficacy. Domperidone penetrates the CNS less, and therefore has less potential for extrapyramidal side effects. Domperidone in high doses, particularly in older individuals, has been linked to QT prolongation and serious cardiac arrhythmias. ${ }^{45,46}$

Does metoclopramide increase the rapidity of drug absorption in migraine? In a small study involving ten patients, the time to reach peak plasma concentration of effervescent acetaminophen and the peak concentration reached were not changed by metoclopramide. ${ }^{47}$ However, other studies have shown an effect on drug absorption. Metoclopramide pre-treatment in migraine attacks increased the serum concentration of tolfenamic acid at
$1.5 \mathrm{~h}$, but its peak concentration, time to peak concentration and the $\mathrm{AUC}_{0-5 \mathrm{~h}}$ remained unchanged as compared with the values obtained with tolfenamic acid alone. ${ }^{48}$

Another study concluded that the impairment of absorption of effervescent ASA during migraine attacks is related to impaired gastro-intestinal motility with delayed gastric emptying, and this impaired motility can be overcome by parenteral metoclopramide. ${ }^{49}$ A clinical trial in which domperidone $20 \mathrm{mg}$ was added to acetaminophen concluded that domperidone shortens the duration of a migraine attack, and may help reduce headache and associated symptoms compared to acetaminophen alone. ${ }^{50}$ In a study involving patients who had failed to obtain adequate relief from a triptan used alone, it was found that sumatriptan $50 \mathrm{mg}$ plus metoclopramide $10 \mathrm{mg}$ provided better relief than sumatriptan alone. It could not be differentiated whether this was due to central dopamine receptor antagonism or to better sumatriptan absorption. ${ }^{51}$

Metoclopramide is a substituted benzamide dopamine $\mathrm{D}_{2}$ antagonist, and at higher doses also a 5- $\mathrm{HT}_{3}$ antagonist. It is also a gastrointestinal pro-kinetic agent through mechanisms that are not fully understood. In addition to metoclopramide and domperidone, other anti-emetics that have been used in migraine include prochlorperazine (a phenothiazine dopamine $\mathrm{D}_{2}$ receptor antagonist), and ondansetron (a 5- $\mathrm{HT}_{3}$ antagonist). Prochlorperazine intravenously is widely used in the emergency room setting for migraine treatment. It is also used orally (10 $\mathrm{mg})$ and rectally $(10-25 \mathrm{mg})$ as an anti-emetic in migraine, but the evidence base for its use is much smaller than that for metoclopramide, and it is more likely to cause extra-pyramidal side effects. The evidence base for use of ondansetron as an antiemetic in migraine is very limited.

Dimenhydrinate is widely available and often used by patients for nausea. It is a complex formulation containing diphenhydramine (an $\mathrm{H}_{1}$ antagonist that mediates the anti-emetic effect), and a theophylline derivative (a CNS stimulant related to caffeine). Dimenhydrinate has some abuse potential. Given the lack of evidence for its efficacy in migraine, metoclopramide, domperidone, and possibly prochlorperazine would appear to be better choices for treatment of migraine-related nausea.

\section{EXPERT CONSENSUS}

$i$. It should be recognized that the response of an individual patient to a specific triptan cannot be predicted with accuracy. Patients with a less than optimal response to their current triptan should be encouraged to try several other triptans in different migraine attacks to determine if they will obtain better relief.

ii. Patients should be encouraged to take their triptan early in their attacks while pain is still mild, although caution may need to be exercised in patients with frequent attacks to avoid medication overuse.

iii. For severe migraine attacks with early vomiting, the use of subcutaneous sumatriptan $6 \mathrm{mg}$ should be considered. Zolmitriptan nasal spray $5 \mathrm{mg}$ may be an alternative choice for some patients. These formulations should also be considered for all patients with severe nausea, particularly those who have nausea early in their attacks, and for attacks not responsive to oral triptan medications. 
iv. For patients with moderate or severe migraine attacks who require triptan therapy, and whose attacks build up rapidly in intensity, rizatriptan $10 \mathrm{mg}$ tablets, eletriptan $40 \mathrm{mg}$ tablets, zolmitriptan $5 \mathrm{mg}$ nasal spray, and sumatriptan $6 \mathrm{mg}$ SC injection should be considered.

v. For patients with moderate or severe attacks who experience side effects on other triptans, almotriptan should be considered.

vi. For patients who experience frequent headache recurrence on triptan therapy, the use of eletriptan or frovatriptan should be considered, or the addition of naproxen sodium to the patient's current triptan.

vii.For patients with nausea or vomiting who require an additional anti-emetic, metoclopramide, domperidone, or if necessary, prochlorperazine can be considered, to be taken with the triptan or triptan-NSAID combination.

\section{Headache Recurrence on Triptans}

The return of headache within 24 hours after initial relief is a difficult parameter to study objectively, because in order to experience headache recurrence patients must have first experienced relief, and the proportion of patients experiencing headache relief varies from drug to drug. If they produce initial headache relief, frovatriptan, naratriptan, and eletriptan may have some advantage in terms of a lower rate of headache recurrence.

Headache recurrence is experienced by $15-40 \%$ of patients taking an oral triptan; in most cases, a second dose of triptan is effective. ${ }^{52}$ Combining a triptan with an NSAID (e.g., sumatriptan plus naproxen sodium) reduces headache recurrence. ${ }^{53}$ In a review of data derived from 31 placebocontrolled major efficacy trials of triptans, it was concluded that triptans with longer half-lives and greater $5-\mathrm{HT}_{1 \mathrm{~B}}$ receptor potency had the lowest rates of headache recurrence. ${ }^{54}$ Mean headache recurrence rates ranged from $17 \%$ for frovatriptan to $40 \%$ for rizatriptan. Dihydroergotamine (DHE), another acute migraine treatment with a long half-life, is also known to have a low headache recurrence rate. ${ }^{55}$

If patients do experience headache recurrence after initial relief from a triptan; the best practice is for the patient to take a second dose of the same triptan. For example, in a study with rizatriptan where headache recurrences were treated with either rizatriptan $10 \mathrm{mg}$ or placebo (median time to recurrence 12 hours), the recurrent headache responded to a second dose of rizatriptan $10 \mathrm{mg}$ in $82 \%$ of patients, versus $44 \%$ for placebo. ${ }^{56}$

\section{EXPERT CONSENSUS}

$i$. When patients experience recurrence of a migraine headache attack after initial headache relief from a triptan, a second dose of the triptan should be recommended.

ii. For patients who experience frequent headache recurrence on triptan therapy, the use of eletriptan, frovatriptan, or dihydroergotamine (DHE) should be considered instead of the patient's current triptan, or the addition of naproxen sodium to the patient's current triptan.

\section{Headache Persistence (triptan failure)}

A related issue is what to advise if the patient's usual triptan dose fails to provide relief during some attacks. The usual advice is that if the initial dose has not provided relief, a second dose will also not be helpful. This is based on two types of evidence. First of all, in a study that tested the ability of zolmitriptan $5 \mathrm{mg}$, $2.5 \mathrm{mg}$ and placebo to successfully treat a moderate or severe persistent headache $2 \mathrm{~h}$ after an initial dose of zolmitriptan 2.5 $\mathrm{mg}$, neither dose of zolmitriptan was superior to placebo for headache response. The placebo response rate at $2 \mathrm{~h}$ after treatment for persistent headache was high at $51.6 \%$, suggesting perhaps that the initial dose of zolmitriptan was still active in reducing headache severity. However, the second dose of zolmitriptan which had been used to treat the persistent headache was clearly no better, with a response rate at $2 \mathrm{~h}$ of $51.6 \%$ for the $5 \mathrm{mg}$ dose, and $49.7 \%$ for the $2.5 \mathrm{mg}$ dose. These results therefore suggested that a second triptan dose two hours after the first dose was no more effective than placebo at providing headache relief. ${ }^{57}$

The other line of evidence comes from dose ranging triptan efficacy trials. Many of these suggest that as the dose of a triptan is increased, after a certain point headache response rates do not increase further. In one trial, for example, 2-h headache response rates for eletriptan $40 \mathrm{mg}$, and $80 \mathrm{mg}$ were $62 \%$, and $59 \%$ respectively, and at $4 \mathrm{~h}$ were $76 \%$, and $79 \%$, respectively. ${ }^{58} \mathrm{In}$ another study, the 2-h headache response rates for zolmitriptan $2.5 \mathrm{mg}, 5 \mathrm{mg}$, and $10 \mathrm{mg}$ were $65 \%, 67 \%$, and $67 \%$, respectively, again showing essentially no increase in headache response rates as the dose was increased over the usual therapeutic dose. ${ }^{59}$ Both these types of data suggest that adding a second triptan dose within a few hours if the first dose is not successful in providing headache relief is not helpful, in sharp contradistinction to the good response that is seen with a second triptan dose when it is taken for headache recurrence. In clinical practice some patients do report relief after taking a second triptan dose for persistent headache, but given the very high placebo response rate observed in this therapeutic situation as discussed above, such anecdotal observations are difficult to interpret. It would seem prudent to use a non-triptan rescue medication if a patient's triptan medication has failed.

\section{EXPERT CONSENSUS}

$i$. When patients experience occasional triptan failure with headache persistence two hours after taking a triptan, a rescue medication from another drug class should be considered, as opposed to dosing again with their triptan.

\section{Timing of Triptan use in Migraine with Aura}

Triptans are known vasoconstrictors, but triptan use during typical migraine auras appears safe. As migraine aura symptoms are likely due to a neurophysiological phenomenon (cortical spreading activation followed by depression) rather than to vasoconstriction, it is not surprising that triptans do not seem to affect a typical migraine aura. In a study where 88 patients used subcutaneous sumatriptan $6 \mathrm{mg}$ during their aura, it was found that sumatriptan given during the aura did not prolong or alter the nature of the migraine aura. ${ }^{60}$ 
A number of clinical trials have shown greater efficacy when a triptan is taken early in the migraine attack. It would seem logical, therefore, to extend this observation and recommend that patients take their triptan during the migraine aura. Two randomized controlled trials, however, suggest that this is not advantageous. When subcutaneous sumatriptan was given during the migraine aura, $68 \%$ of patients went on to develop a moderate or severe headache within six hours, as compared to $75 \%$ of patients with placebo. ${ }^{60}$ This difference was not statistically significant, although the study had only just over 80 patients in each group, and may therefore have been underpowered to detect a difference. Similarly, a study comparing eletriptan $80 \mathrm{mg}$ given during the aura phase with placebo found no significant difference in the proportion of patients developing moderate-to-severe headache within six hours (eletriptan $(61 \%)$ versus placebo (46\%). ${ }^{61}$ This study was also relatively small, with just over 40 patients in each patient group. A third small crossover study using zolmitriptan $20 \mathrm{mg}$ given during the aura found that a migraine headache did not follow the aura in three out of 16 patients, whereas the headache followed the aura in all patients who took placebo. ${ }^{62}$ This small study was interpreted as showing some promise for taking a triptan during the aura, although the response rate is clearly much lower than has been found in other studies when zolmitriptan is taken early in the pain phase of the headache. In summary, although all three of these small randomized studies showed no significant benefit as compared to placebo when a triptan is taken during the aura, none showed any adverse effects of the triptan on the aura.

Patients do anecdotally report success with taking a triptan during their migraine aura. These observations are difficult to interpret, given that in the eletriptan study, $54 \%$ of patients given placebo did not develop a headache afterwards, and similarly in the sumatriptan study $25 \%$ did not develop a headache after placebo. The randomized clinical studies would suggest that triptan treatment during the aura is not beneficial, and that patients should be advised to take their triptan after the aura during the initial part of the pain phase of their migraine. A small recent open label study, however, has suggested that at least for some patients, treatment during the aura may be advantageous. Using sumatriptan RT (fast dissolving formulation), treatment during the aura prevented the development of headache in $89 \%$ of attacks, while treatment during the pain phase within one hour of pain onset in the same patients rendered $79 \%$ of attacks pain free. 63

Triptan product monographs typically state that they are contraindicated in patients with hemiplegic, ophthalmoplegic, and basilar migraine. These contraindications are theoretical and presumably based on the vasoconstrictor actions of triptans, rather than on data. Given that migraine auras appear related to neurophysiological factors and not direct vasoconstriction and the lack of evidence regarding triptan use in these syndromes, the risk which triptans pose is unclear. Clinicians need to be aware of these contraindications. Anecdotally, where they have been tried, patients with hemiplegic migraine do seem to tolerate triptans safely and find them effective. ${ }^{64,65}$

In summary, although small randomized double-blind placebo controlled trials have given no support for triptan use during the migraine aura, this practice appears safe in patients with a typical aura. It would seem appropriate to recommend that patients take their triptan early at onset of the pain phase, but if they find taking their triptan during their aura consistently effective in preventing their headaches, there is no reason to discourage this practice.

\section{EXPERT CONSENSUS}

$i$. Patients with migraine with aura should be advised to take their triptan at the onset of the pain phase, although triptan treatment during typical migraine aura is safe, and if patients find that treatment during the aura is effective, there is no reason to discourage this practice.

\section{Refractory migraine strategies}

\section{a. Triptan-NSAID combination strategy}

The use of sumatriptan and naproxen sodium simultaneously to treat migraine attacks is based on several randomized controlled trials which have shown that the combination is more effective than either drug used alone. ${ }^{66,67}$ Naproxen sodium 500 $\mathrm{mg}$ was used in these trials, and was combined with several different sumatriptan dosages.

A sumatriptan-naproxen sodium combination tablet (not available in Canada) has also been compared to placebo in a patient population that had discontinued a short-acting triptan in the previous year because of poor effectiveness or intolerance. In these randomized double-blind, placebo-controlled, twoattack crossover trials the sumatriptan-naproxen combination tablet provided 2-h pain free results in 40 and $44 \%$ of patients in the two trials, versus 17 and $14 \%$ for placebo. ${ }^{68}$

It would appear reasonable to apply the principle that early treatment during a migraine attack increases effectiveness of the sumatriptan-naproxen combination. In pooled data from two placebo-controlled trials, sumatriptan $85 \mathrm{mg}$ combined with naproxen sodium $500 \mathrm{mg}$ taken early in the attack provided 2-h pain free results in $51.5 \%$ of patients, versus $16 \%$ for placebo. ${ }^{69}$

The sumatriptan-naproxen sodium combination has also been shown to reduce the headache recurrence rate as compared to sumatriptan taken alone. ${ }^{70}$

Although the evidence available is largely confined to sumatriptan-naproxen sodium combinations, it would seem reasonable to generalize from this evidence to other triptanNSAID combinations. Among NSAIDs, naproxen sodium may be particularly suited for combining with most triptans, given its long half-life and duration of action, but other triptan-NSAID combinations may also be effective. Table 9 provides information (doses, cautions, etc) for many medications used for acute migraine treatment.

\section{b. Triptan-NSAID combination with rescue medication strategy}

For some patients, triptans are effective for virtually every attack, particularly if they are taken early when the pain is still of mild intensity. When patients do experience occasional triptan failure, a rescue medication can be helpful and may in some cases prevent emergency department visits. For most patients, it would appear best to use the triptan-NSAID combination strategy before resorting to other rescue medications, although there may be exceptions if patients have only the very occasional triptan failure. 


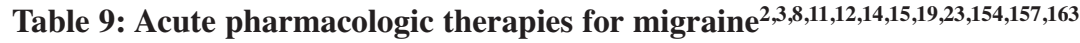

\begin{tabular}{|c|c|c|c|}
\hline Drug class/drug & Dosage (adults) & Selected adverse effects & Comments \\
\hline \multicolumn{4}{|l|}{ Triptans: } \\
\hline Almotriptan (oral tablets) & $\begin{array}{l}6.25 \mathrm{or} 12.5 \mathrm{mg} \text { (optimal dose } \\
12.5 \mathrm{mg}) ; \text { may repeat once after } 2 \mathrm{~h} *(\max . \\
25 \mathrm{mg} / 24 \mathrm{~h})\end{array}$ & $\begin{array}{l}\text { All triptans: } \\
\text { Chest/neck/jaw discomfort or } \\
\text { tightness ("triptan sensations"); } \\
\text { paresthesias }\end{array}$ & $\begin{array}{l}\text { All triptans: } \\
\text { To avoid } \mathrm{MOH} \text {, limit use to not } \\
\text { more than } 9 \text { days/month }\end{array}$ \\
\hline Eletriptan (oral tablets) & $\begin{array}{l}20 \text { or } 40 \mathrm{mg} \text { (optimal dose } 40 \mathrm{mg} \text { ); may repeat } 20 \mathrm{mg} \text { dose once } \\
\text { after } 2 \mathrm{~h} \text {; a } 2^{\text {nd }} 40 \mathrm{mg} \text { dose is not recommended by product } \\
\text { monograph ( } \max .40 \mathrm{mg} / 24 \mathrm{~h} \text { in Canada; } 80 \mathrm{mg} / 24 \mathrm{~h} \text { in U.S.) }\end{array}$ & $\begin{array}{l}\text { If chest discomfort persists or } \\
\text { appears to be cardiac in origin, } \\
\text { consult physician immediately }\end{array}$ & $\begin{array}{l}\text { Contraindicated in cardiovascular, } \\
\text { cerebrovascular, peripheral } \\
\text { vascular disorders, uncontrolled } \\
\text { hypertension }\end{array}$ \\
\hline Frovatriptan (oral tablets) & $2.5 \mathrm{mg}$; may repeat once in $4-24 \mathrm{~h} *(\max .5 \mathrm{mg} / 24 \mathrm{~h})$ & & \\
\hline Naratriptan (oral tablets) & $\begin{array}{l}1 \text { or } 2.5 \mathrm{mg} \text { (optimal dose } 2.5 \mathrm{mg}) \text {; may repeat once after } 4 \mathrm{~h} * \\
(\max .5 \mathrm{mg} / 24 \mathrm{~h})\end{array}$ & & $\begin{array}{l}\text { If no response to first dose of } \\
\text { triptan, do not repeat for that } \\
\text { attack; may repeat dose if partial } \\
\text { effect from first dose (after }\end{array}$ \\
\hline $\begin{array}{l}\text { Rizatriptan [oral tablets, orally dispersible } \\
\text { tablets (RPD }() \text { ] }\end{array}$ & $\begin{array}{l}5 \text { or } 10 \mathrm{mg} \text { (optimal dose } 10 \mathrm{mg}) \text {; may repeat after } 2 \mathrm{~h} *(\max .20 \\
\mathrm{mg} / 24 \mathrm{~h})\end{array}$ & & $\begin{array}{l}\text { appropriate interval) or if } \\
\text { headache recurs after successful } \\
\text { initial response }\end{array}$ \\
\hline $\begin{array}{l}\text { Sumatriptan [oral tablets, fast- } \\
\text { disintegrating tablets (DF), nasal spray, } \\
\text { SC injection] }\end{array}$ & $\begin{array}{l}\text { Oral: } 25,50 \text { or } 100 \mathrm{mg} \text { (optimal dose } 100 \mathrm{mg}) \\
\text { may repeat once after } 2 \mathrm{~h} *(\max .200 \mathrm{mg} / 24 \mathrm{~h}) \\
\text { Nasal: } 5 \text { or } 20 \mathrm{mg}(\text { optimal dose } 20 \mathrm{mg}) \text { in one nostril; may } \\
\text { repeat after } 2 \mathrm{~h}(\max .40 \mathrm{mg} / 24 \mathrm{~h}) \\
\text { SC: } 6 \mathrm{mg} ; \text { may repeat once in } 1 \mathrm{~h}(\max .12 \mathrm{mg} / 24 \mathrm{~h})\end{array}$ & & $\begin{array}{l}\text { Rizatriptan: } \\
\text { Propranolol inhibits metabolism } \\
\text { of rizatriptan: a dose of } 5 \mathrm{mg} \text { is } \\
\text { recommended for patients on } \\
\text { propranolol. }\end{array}$ \\
\hline $\begin{array}{l}\text { Zolmitriptan [oral tablets, orally } \\
\text { dispersable tablets (Rapimelt }\left({ }^{\circledR}\right) \text {, nasal } \\
\text { spray] }\end{array}$ & $\begin{array}{l}\text { Oral: } 1 \mathrm{mg} \text { or } 2.5 \mathrm{mg} \text { (optimal dose } 2.5 \mathrm{mg}) \text {, may repeat once } \\
\text { after } 2 \mathrm{~h} *(\max .10 \mathrm{mg} / 24 \mathrm{~h}) \\
\text { Nasal: } 2.5 \mathrm{mg} \text { or } 5 \mathrm{mg}(\text { optimal dose } 5 \mathrm{mg}) \text { in one nostril; may } \\
\text { repeat once after } 2 \mathrm{~h} *(\max .10 \mathrm{mg} / 24 \mathrm{~h})\end{array}$ & & \\
\hline
\end{tabular}

\section{Ergot derivatives:}

Ergotamine

$(+$ caffeine $)$

Dihydroergotamine (DHE) (nasal spray, injection) (oral tablets)

\section{Oral: 0.5 to $2 \mathrm{mg}$ at onset; then}

$1 \mathrm{mg} \mathrm{q} 1 \mathrm{~h}$ prn $\mathrm{X} 3$ doses ( $\max$.

$6 \mathrm{mg} / 24 \mathrm{~h}$ ); once an effective and tolerated dose has been established (usually between 0.5 and $2 \mathrm{mg}$ ), the whole dose should be taken at one time early in the attack

Nasal: $0.5 \mathrm{mg}$ ( 1 spray) in each nostril; repeat in $15 \mathrm{~min}$ if no effect (max.

$4 \mathrm{mg} / 24 \mathrm{~h})$

SC/IM: 0.5 or $1 \mathrm{mg}$; may repeat in $1 \mathrm{~h}(\max .3 \mathrm{mg} / 24 \mathrm{~h})$; maybe given IV (in hospital)

\section{Ergotamine: nausea, vomiting, paresthesias, cramps, vasoconstriction, ergot dependence, ergotism}

$D H E$ : same as for ergotamine but less potent vasoconstriction DHE nasal: rhinitis, nausea, taste disturbance
Ergotamine: Very limited role for ergotamine; to avoid $\mathrm{MOH}$, limit use to not more than 9 days/month

All ergot derivatives: Many contraindications (e.g., cardiovascular, peripheral vascular disorders; pregnancy)

Avoid concomitant use with potent CYP3A4 inhibitors (e.g., macrolide antibiotics, protease inhibitors)

Avoid concomitant use with other vasoconstrictors

Caution in elderly (due to vasoconstriction)

Antiemetic (e.g.

metoclopramide) may be required with parenteral DHE

\begin{tabular}{|c|c|c|c|}
\hline \multicolumn{4}{|l|}{ Analgesics/NSAIDs: } \\
\hline Acetaminophen & $1,000 \mathrm{mg}(\max .4 \mathrm{~g} /$ day $)$ & $\begin{array}{l}\text { Acetaminophen: Hepatotoxicity } \\
\text { with acute overdose or chronic }\end{array}$ & Simple analgesics/NSAIDs: \\
\hline Acetylsalicylic acid (ASA) & $975-1,000 \mathrm{mg}$ & use of high doses ( $>4 \mathrm{~g} /$ day) & $\begin{array}{l}\text { simple analgesics or NSAIDs to } \\
\text { not more than } 14 \text { days/month }\end{array}$ \\
\hline Ibuprofen & $400 \mathrm{mg}$ & $\begin{array}{l}\text { ASA/NSAIDs: GI irritation, renal } \\
\text { toxicity, hypertension; avoid if }\end{array}$ & \\
\hline Naproxen sodium & 500 or $550 \mathrm{mg}$ (up to $825 \mathrm{mg}$ ) & ASA-induced asthma or GI ulcers & \\
\hline Diclofenac potassium & $50 \mathrm{mg}(\max .100 \mathrm{mg})$ & & All opioids: \\
\hline $\begin{array}{l}\text { Opioid- and/or barbiturate (i.e., } \\
\text { butalbital)-containing products: }\end{array}$ & & $\begin{array}{l}\text { All opioids: } \\
\text { CNS depression, sedation, } \\
\text { respiratory depression, tolerance, } \\
\text { dependence, abuse, possible }\end{array}$ & $\begin{array}{l}\text { Limit use of opioid-containing } \\
\text { products to refractory cases, with } \\
\text { close monitoring of usage. }\end{array}$ \\
\hline $\begin{array}{l}\text { Butorphanol nasal spray (not } \\
\text { recommended - use in exceptional cases } \\
\text { only) }\end{array}$ & $\begin{array}{l}1 \mathrm{mg} \text { ( } 1 \text { spray) in one nostril; may repeat once in } 60-90 \mathrm{~min} \text {, if } \\
\text { adequate pain relief is not achieved; this } 2 \text {-dose sequence can be } \\
\text { repeated in } 4-6 \mathrm{~h} \text {, if necessary }\end{array}$ & addiction & $\begin{array}{l}\text { Butorphanol: limit use to not } \\
\text { more than } 7 \text { days/month }\end{array}$ \\
\hline $\begin{array}{l}\text { Opioid combination products: } \\
\text { (e.g., acetaminophen + tramadol; } \\
\text { acetaminophen/ASA + caffeine + } \\
\text { codeine; }\end{array}$ & $\begin{array}{l}\text { Opioid combination products: } \\
\text { Individualized dosing (use lowest effective dose) }\end{array}$ & & $\begin{array}{l}\text { Tramadol and codeine-containing } \\
\text { products: limit use to no more } \\
\text { than } 9 \text { days a month }\end{array}$ \\
\hline
\end{tabular}




\begin{tabular}{|c|c|c|c|}
\hline $\begin{array}{l}\text { Butalbital-containing products: } \\
\text { (i.e., ASA + butalbital + caffeine } \pm \\
\text { codeine) (not recommended - use in } \\
\text { exceptional cases only) }\end{array}$ & $\begin{array}{l}\text { Butalbital-containing products: } \\
\text { Individualized dosing (use lowest effective dose) }\end{array}$ & $\begin{array}{l}\text { Butalbital-containing products: } \\
\text { sedation, dependence, abuse, } \\
\text { possible addiction; withdrawal } \\
\text { syndrome after discontinuing high } \\
\text { doses }\end{array}$ & $\begin{array}{l}\text { Butalbital)-containing products: } \\
\text { Little evidence for efficacy; } \\
\text { strong risk of overuse; avoid } \\
\text { except in exceptional } \\
\text { circumstances, with close } \\
\text { monitoring of usage; suggest } \\
\text { limiting use to not more than } 7 \\
\text { days/month }\end{array}$ \\
\hline \multicolumn{4}{|l|}{ Adjunctive drugs: } \\
\hline Metoclopramide & $\begin{array}{l}10 \mathrm{mg} \text { orally (may repeat up to } 4 \text { doses } / 24 \mathrm{~h} \text { ); single doses of } 20 \\
\text { mg may be used, if necessary. }\end{array}$ & $\begin{array}{l}\text { Metoclopramide: } \\
\text { drowsiness, extrapyramidal } \\
\text { effects }\end{array}$ & $\begin{array}{l}\text { May be combined with acute } \\
\text { therapies }\end{array}$ \\
\hline Domperidone & $\begin{array}{l}10 \mathrm{mg} \text { orally (may repeat up to } 4 \text { doses } / 24 \mathrm{~h} \text { ); single doses of } 20 \\
\text { mg may be used, if necessary. }\end{array}$ & $\begin{array}{l}\text { Domepridone: } \\
\text { QT prolongation }\end{array}$ & \\
\hline Prochlorperazine & $\begin{array}{l}10 \mathrm{mg} \text { orally (may repeat up to } 4 \text { doses } / 24 \mathrm{~h} \text { ) or } \\
10-20 \mathrm{mg} \text { rectally** (may repeat up to } 4 \text { doses of } 10 \mathrm{mg} \text { or } 2 \\
\text { doses of } 20 \mathrm{mg} / 24 \mathrm{~h} \text { ) }\end{array}$ & $\begin{array}{l}\text { Prochlorperazine: } \\
\text { drowsiness, dizziness, } \\
\text { extrapyramidal effects }\end{array}$ & \\
\hline
\end{tabular}

$\mathrm{MOH}=$ medication overuse headache; GI = gastrointestinal; * Second dose may be taken if headache recurs after initial relief or if partial response to first dose (after specified time interval); if there is no response to first dose, 2nd dose should not be taken for that attack (may take drug for subsequent attacks); ** Rectal prochlorperazine is available in $10 \mathrm{mg}$ strength only

There are several issues which make selection of an effective rescue medication for refractory migraine attacks difficult.

These include:

1. Many migraine sufferers with a refractory migraine attack have nausea and/or vomiting to a degree which may make it difficult to take oral medications effectively.

2. Many medications are more effective when given parenterally, particularly intravenously (e.g., metoclopramide, prochlorperazine, chlorpromazine, and ketorolac). Intravenous medications are not an option in the home setting, although patients can be trained to give themselves subcutaneous or intramuscular injections. Delivery of medication rectally (by suppository) in patients with vomiting (e.g., prochlorperazine) is also an option.

3. There is concern that opioid use may result in long term receptor changes in patients with migraine and lead to less responsiveness to other drugs (triptans and NSAIDs). It was found in a small case series that migraine patients with prior opioid exposure did not respond as well to intravenous ketorolac $30 \mathrm{mg}$ than patients with no prior history of opioid treatment. ${ }^{71}$ Nevertheless, it remains unclear how clinically important receptor changes related to occasional opioid use might be in the long term in migraine management. There is also concern about the propensity of opioids to lead to escalation of use over time, and to medication overuse headache. Opioids should therefore not be used routinely in migraine, but are one option for rescue medication for occasional use when a patient's triptan fails.
Choosing a rescue medication for triptan failure is problematic in that triptans are vasoconstrictors, and as a result other vasoconstrictors (other triptans, dihydroergotamine, and ergotamine) are not recommended within 24 hours of the previous triptan dose (according to product information for triptans). The rescue medication choices that remain are somewhat limited. Available options for use at home include several classes of medications:

1. NSAIDs (oral and injectable): Oral NSAIDs are unlikely to provide adequate pain relief in patients who have failed triptan therapy, but may provide some relief, and may be useful in combination with dopamine antagonists. Among the NSAIDs, when patients have severe nausea or vomiting, intramuscular (IM) ketorolac is most likely to be helpful in the home setting provided that it can be administered safely. Ketorolac $60 \mathrm{mg}$ IM has been shown to be as effective as a combination of meperidine $50-100 \mathrm{mg}$ with an anti-emetic. Ketorolac $30 \mathrm{mg}$ IM appears to be less effective. ${ }^{72}$ Whether IM ketorolac $60 \mathrm{mg}$ can be used safely at home has been studied. In an open label clinical trial, 16 patients with episodic migraine administered 61 separate injections of ketorolac at home. The authors found that after appropriate training, patients were able to administer the ketorolac safely. Sixty-four percent of ketorolac injections in this open-label studies provided relief classified as "good". All patients had a history of frequent emergency room visits, and improvement was sufficient in $87 \%$ of ketorolac administrations in the study that an emergency room visit could be avoided. Of interest, 13 of the 16 patients had previously been IM dihydroergotamine treatment failures. For safety reasons, patients with a history of gastritis, ulcer, esophagitis, renal 
insufficiency, or sensitivity to any non-steroidal were excluded. ${ }^{73}$ Self-injection of ketorolac has not been widely used in Canada, but this small study suggests that it is an option which can be considered as a rescue medication in patients with triptan failure. If patients have already taken naproxen sodium or another NSAID as part of the triptan-NSAID combination strategy, consideration will need to be given to the time elapsed since the last NSAID dose, as ketorolac is also an NSAID.

As many migraine patients with refractory attacks will have nausea or even vomiting, an IM medication is an attractive option for home rescue. Rapidity of drug absorption is also an important factor, and with IM ketorolac, peak blood levels occur within 45 minutes. Combining it with an anti-emetic (e.g., rectal prochlorperazine) may be helpful.

Indomethacin is another option for rescue therapy in refractory migraine when triptans have failed. It has been studied as a combination drug with caffeine and prochlorperazine). In a double-blind randomized controlled study without placebo, an oral formulation of the three drugs (indomethacin $25 \mathrm{mg}$, prochlorperazine $2 \mathrm{mg}$, and caffeine $75 \mathrm{mg}$ ) was as effective as sumatriptan $50 \mathrm{mg}$ for the $2-\mathrm{h}$ pain free endpoint in migraine. Interestingly, when taken as a rescue medication at $2 \mathrm{~h}$ because of treatment failure, it appeared more efficacious than sumatriptan $50 \mathrm{mg}^{74}$ In another study using suppository formulations for both the three-drug combination (indomethacin $25 \mathrm{mg}$, prochlorperazine $4 \mathrm{mg}$, and caffeine $75 \mathrm{mg}$ ) and for sumatriptan $25 \mathrm{mg}$, the three-drug combination provided a 2-h pain-free rate of $47 \%$ versus $35 \%$ for sumatriptan, and a 48 -h sustained pain free response of $39 \%$ versus $32 \%$ for sumatriptan. ${ }^{75}$ In summary, indomethacin in combination with prochlorperazine might be a useful rescue medication in patients with triptan failure. The combination medications used in the studies referenced above are not available in Canada, but indomethacin suppositories and prochlorperazine tablets and suppositories are individually available, and the suppositories could be used even in the presence of vomiting. In the context of a rescue medication, doses of indomethacin $50 \mathrm{mg}$ and prochlorperazine $10 \mathrm{mg}$ orally would appear appropriate. If suppositories are used, indomethacin 50 to $100 \mathrm{mg}$ and prochlorperazine 10 to $25 \mathrm{mg}$ might be useful (but see below re doses available in Canada).

2. Dopamine antagonists (prochlorperazine, meto-clopramide, and chlorpromazine): The effectiveness of a number of dopamine antagonists given intravenously in refractory migraine attacks has been well established. ${ }^{76}$ Given orally, these medications are helpful as anti-emetics, but much less useful in actually aborting the migraine attack. Prochlorperazine given as a suppository in a dose of 10 - $25 \mathrm{mg}$ can be helpful, particularly if the migraine attack is accompanied by nausea and vomiting. The efficacy of prochlorperazine $25 \mathrm{mg}$ suppositories in acute migraine has been studied in an emergency department in a randomized, double-blinded, placebo-controlled study. Prochlorperazine was statistically superior to placebo, and the authors concluded that the $25 \mathrm{mg}$ rectal suppository provided excellent pain relief within $2 \mathrm{~h}$ in patients with acute migraine. ${ }^{77}$ The $25 \mathrm{mg}$ suppository can be given twice a day. In Canada, only the $10 \mathrm{mg}$ prochlorperazine suppository is available, but two can be used simultaneously to approximate doses used in the study above. A related drug, chlorpromazine, could also be considered, as chlorpromazine both intravenously ${ }^{76}$ and intramuscularly ${ }^{78}$ has been reported to be helpful in acute migraine. Like prochlorperazine, it is a powerful antiemetic, and its sedative effects may also be helpful. No published studies on chlorpromazine suppositories in acute migraine treatment have been located, and chlorpromazine suppositories are not generally available in Canada.

3. Corticosteroids: Short-term high dose steroid treatment has a time-honoured place in the treatment of status migrainosus (or status migraine), although there is a lack of randomized controlled trials. It might therefore be considered for a refractory migraine attack that has failed to respond to the patient's usual acute medication. Reviews on this subject typically state that corticosteroids are commonly used as therapy for status migraine, and that short courses of rapidly tapering doses of oral corticosteroids (prednisone or dexamethasone) are thought to alleviate status migraine. ${ }^{79}$ By extension, a short course of prednisone or dexamethasone (starting with a high dose of prednisone 50 or $60 \mathrm{mg}$ on the first day and tapering over two or three additional days, or dexamethasone $8 \mathrm{mg}$ on the first day, and tapering over two or three days) might be helpful as a rescue medication in a refractory migraine attack. Frequency of use should be limited to once a month or less.

Much of the research in this area has been done in emergency departments where dexamethasone has been assessed for its ability to prevent headache recurrence after acute migraine attack treatment with other drugs. A meta-analysis of available data concluded (in 2008) that when added to standard abortive therapy for migraine headache in the emergency room, a single parenteral dose of dexamethasone is associated with a $26 \%$ relative reduction in headache recurrence $(\mathrm{NNT}=9)$ within 72 hours. ${ }^{80}$

Whether dexamethasone alone can reduce migraine intensity is less clear, but there is some evidence that it can. In a doubleblind, randomized controlled study involving 190 patients in an emergency department, it was found that dexamethasone $8 \mathrm{mg}$ IV reduced headache intensity more at 60 minutes and 24 hours post intervention than a relatively small dose of morphine $(0.1 \mathrm{mg} / \mathrm{kg}) \mathrm{IV} .{ }^{81}$ Perhaps the best evidence that dexamethasone is potentially useful as a rescue medication in acute migraine attacks is data from a randomized, double-blind, cross-over study which compared rizatriptan $10 \mathrm{mg}$ alone to dexamethasone $4 \mathrm{mg}$ orally alone and to the combination of rizatriptan $10 \mathrm{mg}$ and dexamethasone $4 \mathrm{mg}$ in patients with menstrually related migraine attacks. The combination of the two medications was superior for both 24-h sustained pain relief and 24-h sustained pain free endpoints. For attacks treated with dexamethasone alone, the 24-h sustained pain relief endpoint was met in $33.3 \%$ of attacks. The significance of this result is difficult to assess in the absence of a placebo group, but the authors concluded that the use of dexamethasone alone in the treatment of menstrually related migraine attacks was not justified by their data. ${ }^{82}$ In patients who received the rizatriptan $10 \mathrm{mg}$ - dexamethasone $4 \mathrm{mg}$ combination, $50.7 \%$ met the 24-h sustained pain-free endpoint, versus only $32.2 \%$ of those who received rizatriptan alone $(\mathrm{p}<0.05)$. Therefore, it might be expected, although not proven, that dexamethasone $4 \mathrm{mg}$ taken several hours after a failed triptan treatment might confer clinically significant benefit. 
4. Opioids and opioid-containing combination analgesics: There are many reasons to avoid opioids in migraine therapy including:

a. Not many comparison trials between oral opioids and other acute medications for migraine have been done, but clinical trials that are available including those using parenteral medications have shown that opioids are generally not superior in headache relief as compared to many other acute pharmacological therapies ${ }^{.72,83}$

b. Recent opioid use may render migraine specific medications less effective. In a post-hoc pooled analysis of rizatriptan trials, patients with prior opioid use within several months prior to taking rizatriptan showed a lower response rate to rizatriptan. ${ }^{84}$ In a study with intravenous ketorolac given relatively late in the migraine attack, patients with a history of prior opioid use tended not to become pain free as compared to patients without a history of prior opioid use. ${ }^{71}$

c. Among acute migraine medications, opioids place patients at relatively high risk for medication overuse headache, particularly with use at frequencies of eight days a month or more ${ }^{85}$ There is evidence that opioids induce persistent pronociceptive trigeminal neural adaptations, which may be of concern in patients with migraine. ${ }^{86}$

Nevertheless, opioids are widely (and often inappropriately) used in Canada as acute migraine medications. In 2005, in a nation-wide population-based sample of Canadians with migraine, $21 \%$ listed a combination analgesic which contained codeine as their primary acute migraine medication. ${ }^{7}$ Combination analgesics with acetaminophen, codeine, and caffeine, although not recommended for routine use, are an option for occasional use as a rescue medication, with the reservations noted above. If opioid-containing combination analgesics are used, tramadol may be a better choice than codeine, given its dual mode of action with binding to $\mu$-opioid receptors, and serotonin and norepinephrine reuptake inhibition. The use of codeine is potentially problematic as it is a relatively inactive pro-drug, and its analgesic effect is dependent upon its conversion into morphine (via CYP2D6). As a result, it is ineffective in 7 to $10 \%$ of the white population because of homozygosity for the nonfunctional mutants of the CYP2D6 alleles. On the other hand, many individuals, depending on ethnic background (ranging from $2-3 \%$ in Europe to $40 \%$ in North Africa) are ultra-rapid metabolizers of codeine and experience a much greater effect of the drug (including both analgesic effects and side effects), because larger amounts of morphine are produced. ${ }^{87}$ Tramadol has some direct analgesic effect from the parent drug. Because it also has an active metabolite which is more potent on the $\mu$ opioid receptor than tramadol itself, those who have higher CYP2D6 activity will have an increased analgesic effect, while those with less CYP2D6 activity will experience less analgesia. ${ }^{88}$

Combination analgesics with barbiturates (with or without opioids) are best avoided because of risk of medication overuse headache which may occur at relatively low frequencies of use (as low as five days of use a month). ${ }^{89}$ If they are used under exceptional circumstances, careful monitoring of frequency of use both by patient diary and by prescriptions is highly recommended.
Strong oral opioids (e.g., morphine, hydromorphone, oxycodone) are best avoided in migraine, if possible, but they may be an option for infrequent use (suggest limiting use to not more than seven days per month) as a rescue medication for the occasional patient (including oxycodone-acetaminophen combinations). Careful patient selection is important, and monitoring of frequency of use with headache diaries is recommended (Canadian Guideline for Safe and Effective Use of Opioids for Chronic Non-Cancer Pain available at: http:// nationalpaincentre.mcmaster.ca/opioid/).

Although not recommended for routine use, intranasal butorphanol is another opioid option for occasional use (suggest limiting use to not more than seven days per month) as a rescue medication when the patient's regular medication fails. It has the advantage that, as a nasal spray, it can be used during severe attacks even if the patient is vomiting. It may therefore reduce the need to attend an emergency department for parenteral medications. Intranasal butorphanol does have a significant risk for drug dependency ${ }^{90}$, and can cause significant sedation and dysphoria. The usual dosage is $1 \mathrm{mg}$ (one spray) in one nostril, with a second dose $(1 \mathrm{mg})$ taken in 60 to 90 minutes, if adequate pain relief is not achieved. This two-dose sequence can be repeated in four hours, if necessary. If used at all, butorphanol should be considered only for carefully selected patients, and careful monitoring of use by the prescribing physician is essential to ensure that escalation in frequency of use is not occurring.

Sleep often helps to terminate a migraine attack and if opioids help to induce sleep, this has the potential to be beneficial. Barbiturate-containing combination analgesics are not recommended, however, because of risk of sedation, cognitive side effects and medication overuse headache..$^{91}$ Of interest, however, in a randomized double-blind placebo-controlled trial in patients discharged after treatment in the emergency department, secobarbital $100 \mathrm{mg}$ to be taken on arrival at home, with a second dose to be taken an hour later if not asleep, resulted in a sustained 24-h headache relief of $94 \%$, as compared to $50 \%$ for placebo. ${ }^{92}$ However, based on minimal evidence for efficacy and the high risk of side effects and overuse, barbiturates are not recommended as a treatment option for acute migraine.

In summary, finding an effective rescue medication for refractory attacks in patients where their usual triptan medication or triptan-NSAID combination has failed can be problematic. A number of potential options, many of them without an adequate evidence base, are listed in Table 10. Anecdotally, occipital nerve blockade with local anesthetics can also be helpful in terminating acute migraine attacks, but controlled trials are lacking, and it is not a practical option for home use.

\section{EXPERT CONSENSUS}

i. For patients whose response to triptans alone is inadequate, an NSAID (e.g., naproxen sodium 500 - 550 $m g)$ should be used simultaneously with their triptan.

ii. For patients with nausea, or where poor drug absorption is suspected, oral metoclopramide $10 \mathrm{mg}$ or domperidone $10 \mathrm{mg}$ can be given with the triptan.

iii. For patients with severe migraine attacks where their triptan or triptan-NSAID combination occasionally fails to provide adequate relief, a rescue plan should be 
discussed with the patient. This may include a rescue medication to be taken at home when their usual medication fails.

$i v$. In providing a rescue medication, the patient needs to be carefully assessed, and the medication tailored as much as possible to the patient's needs. For parenteral formulations, careful patient training is essential, and consideration should be given as to whether the patient can safely administer the medication.

v. For many rescue medications, in particular opioids and dexamethasone, frequency of use should be carefully monitored to ensure patient safety, and in the case of opioids to avoid medication overuse headache, abuse, dependence and possible addiction.

vi. Rescue medications that can be considered, either alone or in combination, include:

a. NSAIDs with or without an anti-emetic, including ketorolac $60 \mathrm{mg}$ by IM self-injection and rectal indomethacin

b. Dopamine antagonists including prochlorperazine suppositories

c. Oral dexamethasone or another steroid, either as a single dose or a short steroid taper over several days d. Tramadol or codeine-containing combination analgesics (limit use to not more than 9 days a month)

$e$. Other opioids (suggest limiting use to not more than seven days per month)

vii.Migraine attack preventive management options, both pharmacological and behavioural, should be considered for all patients where acute therapy is not adequately successful or the patient is at risk of medication overuse headache.

\section{c. Dihydroergotamine strategy}

Dihydroergotamine (DHE)

Dihydroergotamine (DHE) has a similar mode of action to the triptans, and is a $5 \mathrm{HT}_{1 \mathrm{~B}}$ and $5 \mathrm{HT}_{1 \mathrm{D}}$ agonist. Unlike the triptans, it also acts on a number of other receptor subtypes, and this may be why some patients who do not respond well to the triptans respond to DHE. Dihydroergotamine is also associated with a lower headache recurrence rate than most triptans. Because DHE, like other ergotamines, is a vasoconstrictor, it is not an option as a rescue medication for triptan failure unless 24 hours have elapsed since the triptan was last taken. ${ }^{93-95}$

Dihydroergotamine is an option for primary therapy for patients without contraindications who do not respond well to

Table 10: Potential rescue medications in patients with occasional triptan failure (or failure of triptan-NSAID combination therapy)*

\begin{tabular}{|c|c|}
\hline Medication & Comments \\
\hline \multicolumn{2}{|l|}{ NSAIDs: } \\
\hline $\begin{array}{l}\text { Oral naproxen sodium, ibuprofen, or diclofenac potassium } \\
\text { (all may be combined with oral metoclopramide or } \\
\text { oral/rectal prochlorperazine) }\end{array}$ & Less likely to be effective as a rescue medication \\
\hline Ketorolac $(60 \mathrm{mg}) \mathrm{IM}$ & Requires patient training in safe injection technique \\
\hline $\begin{array}{l}\text { Indomethacin oral or rectal with or without } \\
\text { prochlorperazine }\end{array}$ & Limited evidence \\
\hline \multicolumn{2}{|l|}{ Dopamine antagonists: } \\
\hline Prochlorperazine oral or rectal & May be used in combination with NSAIDs \\
\hline Chlorpromazine oral & Sedation and anti-emetic properties may be useful \\
\hline \multicolumn{2}{|l|}{ Steroids: } \\
\hline Dexamethasone / prednisone oral & $\begin{array}{l}\text { Limited evidence. Limit to short courses (single dose or } \\
\text { several days), and limit frequency of use. }\end{array}$ \\
\hline \multicolumn{2}{|r|}{ 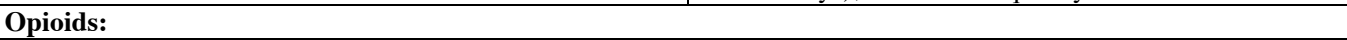 } \\
\hline Combination analgesics with tramadol & $\begin{array}{l}\text { Monitor use - risk of medication overuse - limit to } 9 \\
\text { days a month or less }\end{array}$ \\
\hline Combination analgesics with codeine & $\begin{array}{l}\text { Monitor use - risk of medication overuse }- \text { limit to } 9 \\
\text { days a month or less }\end{array}$ \\
\hline Intranasal butorphanol & $\begin{array}{l}\text { Best avoided - monitor frequency of use closely - high } \\
\text { risk of addiction, medication overuse - select patients } \\
\text { carefully, limit use to no more than } 7 \text { days a month }\end{array}$ \\
\hline Combination analgesics with barbiturates & $\begin{array}{l}\text { Best avoided, use only in exceptional circumstances - } \\
\text { monitor use - high risk of addiction, medication overuse }\end{array}$ \\
\hline Strong opioids (morphine, hydromorphone, oxycodone) & $\begin{array}{l}\text { Best avoided, use only in exceptional circumstances - } \\
\text { monitor use - high risk of addiction, medication overuse, } \\
\text { limit to no more than } 7 \text { days a month }\end{array}$ \\
\hline
\end{tabular}

*For additional information on drug dosages, etc, see discussion of Strategy 3b: Triptan-NSAID combination with rescue medication strategy. 
the triptans, but unfortunately is not readily absorbed after oral administration. It is therefore only available as a nasal spray and by injection. The side effects of DHE and other ergots reflect their agonist activity at $5-\mathrm{HT}_{1 \mathrm{~A}}$ (nausea, dysphoria), 5- $\mathrm{HT}_{2 \mathrm{~A}}$ (peripheral vaso-constriction), and dopamine $\mathrm{D}_{2}$ (nausea, vomiting) receptors. ${ }^{93}$ Idiosyncratic fibrotic complications involving the lung, heart, and retroperitoneum are serious but very rare side effects which appear to be linked to $5-\mathrm{HT}_{2}$ agonism. $^{96}$

Dihydroergotamine is associated with less potent vasoconstriction (peripheral arteries), less nausea and vomiting, and a lower risk of medication overuse headache compared with ergotamine. ${ }^{97}$ However, both ergotamine and DHE were comparable in terms of vasoconstriction in human coronary arteries. ${ }^{98} \mathrm{DHE}$ has a central effect in the brainstem, which may result in enhanced efficacy in migraine. ${ }^{99}$ It is available in intranasal (IN) and parenteral formulations [for intravenous (IV), intramuscular (IM) or subcutaneous (SC) use]. Oral DHE is not available in Canada.

Peak plasma DHE levels occur in 30-60 min with the IN formulation. ${ }^{93}$ An orally inhaled form (delivered with a novel inhaler using a breath-triggered, synchronized mechanism) is currently being studied in phase III clinical trials; it appears to be promising. ${ }^{96}$ IV DHE, usually given with an IV antiemetic, is useful for severe attacks in the emergency department. The IV route will not be discussed further in this guideline. DHE may

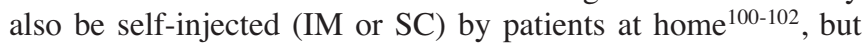
individual patient instruction in proper injection technique is required as an auto-injector is not available. Peak plasma levels occur within 24 minutes with IM or SC administration. ${ }^{96}$

Nasal DHE is typically administered as follows: One spray $(0.5 \mathrm{mg})$ in each nostril, repeated after 15-30 minutes. Not all the medication is absorbed, and therefore the total dose is $2 \mathrm{mg}$, as compared to the usual $1 \mathrm{mg}$ dose when DHE is used by injection. It is recommended that patients not use more than eight sprays in 24 hours or 24 sprays in one week. Subcutaneous or intramuscular self-injection of DHE provides more certain drug absorption than the intranasal route. Patients are typically trained to administer the DHE injections in the lateral thigh. The usual dose is $1 \mathrm{mg}$ of DHE, but this can be reduced to $0.5 \mathrm{mg}$ if nausea is a problem. Metoclopramide $10 \mathrm{mg}$ taken orally 30 minutes before the DHE injection is often used routinely to reduce nausea. If injection-site burning is a problem, patients can be shown how to dilute the DHE by adding $0.5 \mathrm{ml}$ of normal saline to $1 \mathrm{~mL}$ of DHE solution. ${ }^{100}$ Patients should be cautioned to reduce the dose or discontinue DHE if leg cramps become a problem, or if they experience coldness or tingling in the hands and feet in association with the injections. An information sheet instructing patients how to self-administer DHE by subcutaneous injection has been published. ${ }^{103}$

Dihydroergotamine injections can be used on an as needed basis, similar to the triptans. Similar to triptans and ergotamine, it is best not to exceed use on nine days a month, although, unlike other acute headache medications, DHE may not cause medication overuse headache. ${ }^{94}$ For prolonged refractory migraine attacks, or if the DHE is used as a bridging medication during detoxification from medication overuse, the DHE can be administered by self-injection twice daily for three or four days, occasionally longer, and then on an as needed basis. Patients should monitor carefully for side effects, as DHE used in this way exceeds the usual dosage recommendations. The usual recommended dose for subcutaneous or intramuscular use is 1 $\mathrm{mg}$, and this can be repeated, as needed, at one hour intervals to a total dose of $3 \mathrm{mg}$ in a 24 hour period. It is recommended that the total weekly dosage not exceed $6 \mathrm{mg}$. Nevertheless, headache specialists have for many years administered DHE for a number of days at dosages from 0.5 to $1 \mathrm{mg}$ three times a day in inpatient settings, thereby exceeding the recommended maximum weekly dose. ${ }^{104,105}$

To summarize, when DHE is used on an outpatient basis by self-injection, the dose should likely be limited to no more than $3 \mathrm{mg}$ per day, administered in $1 \mathrm{mg}$ doses if tolerated. Although daily injections can be used for several days if necessary in responsible patients with refractory headache attacks who are able to monitor for side effects, this should be limited to preferably two or a maximum of three $1 \mathrm{mg}$ injections per day, usually for a maximum period of three to four days. However, in refractory patients longer courses of daily injections are sometimes used. Dihydroergotamine can be used on as needed basis thereafter. It would appear prudent to limit long term DHE use to nine days a month, although it is unclear whether DHE causes medication overuse headache in migraine sufferers. As all other acute medications do, caution with regard to frequency of DHE use is advised.

\section{Ergotamine}

Ergotamine, introduced in the early 1900s, was the first migraine-specific agent. It is a potent serotonin $5-\mathrm{HT}_{1 \mathrm{~B} / 1 \mathrm{D}}$ receptor agonist ${ }^{106}$, and has also been shown to inhibit neurogenic inflammation in animals. ${ }^{93}$ Rectal and sublingual dosage forms are no longer available in Canada, with only an oral tablet formulation (in combination with caffeine) currently available. Oral bioavailability of ergotamine is very poor due to extensive first pass metabolism. Caffeine is believed to enhance absorption of ergotamine. ${ }^{107}$ Use of oral ergotamine is limited by side effects (in particular nausea), and limited efficacy. It is difficult to titrate oral ergotamine to an effective but subnauseating dose.${ }^{96}$ Ergotamine is a potent vasoconstrictor (alphaadrenergic effect) and is associated with peripheral and coronary vasoconstriction. It is also associated with a risk of ergotism, and a high risk of medication overuse headache. Its use must be limited to less than ten days per month. ${ }^{108} \mathrm{~A}$ meta-analysis of studies has concluded that the adverse effects of ergotamine outweigh any benefits..$^{95,109}$

Because ergotamine is not recommended for routine use, we have not provided an ergotamine strategy in this guideline. An expert consensus panel which reviewed the use of ergotamine (in the year 2000) concluded that there remains a place for ergotamine in modern clinical practice but only when used carefully. ${ }^{95}$ The authors concluded that it remains useful for a limited number of migraine sufferers who have prolonged attacks or in whom headache recurrence is a substantial issue. It was felt that a triptan was a better option for most migraine sufferers requiring migraine specific medication both from an efficacy and side effect perspective. Given that there are more triptans available today than there were in 2000 , it is likely that the place of ergotamine in migraine therapy today is even more limited. The same authors recommended a dose of 0.5 to $2 \mathrm{mg}$, 
and once the patient's dosage is established, the whole dose should be taken at one time as early in the attack as practical. The objective is to find a dose which is effective but which has as few side effects as possible. A smaller dose can be tried initially, and this can be increased in subsequent attacks to determine the dose required to produce headache relief. Ergotamine can also be tested for tolerability with regard to nausea between attacks to assist in the process of finding the correct dose for the patient.

\section{EXPERT CONSENSUS}

i. Dihydroergotamine (DHE) by nasal spray [one spray $(0.5$ $m g$ ) in each nostril, repeated once after 15 - 30 minutes; maximum daily dose eight sprays) or self-injection (0.5 - 1 mg; maximum daily dose $3 \mathrm{mg}$ ) is an option for acute migraine therapy for patients who do not respond well to triptan-NSAID combination therapy (but not as a rescue therapy as it is also a vasoconstrictor).

ii. DHE self-injection (SC or IM) requires individual patient training in safe injection techniques, but provides more reliable drug absorption than the intranasal route.

iii. Oral ergotamine is not recommended for routine use, but remains an option for a small proportion of patients with prolonged headache attacks and / or frequent headache recurrence who do not respond well to the triptans and for whom DHE is not an option. When used, once an effective and tolerated dose has been determined (usually between 0.5 and $2 \mathrm{mg}$ ), the entire dose should be taken early in the headache attack to maximize effectiveness.

\section{Vasoconstrictor unresponsive or contraindicated strategy}

The triptans and DHE are the most effective medications for many patients with severe migraine attacks, but a significant proportion of patients with migraine do not respond to these medications. For others, these medications may be contraindicated, primarily because of cardiovascular disease. The treatment options for both of these patient groups are similar, although for healthy migraine patients without cardiovascular disease, cardiovascular safety of NSAIDs will be less of an issue. The discussion below will focus on patients with contraindications to triptans, but options are similar for healthy patients who are triptan-DHE unresponsive.

For patients with contraindications to vasoconstrictors, the NSAIDs (including ASA) and acetaminophen, with or without metoclopramide, remain first line therapy (see strategy 1a: acetaminophen strategy and strategy $1 \mathrm{~b}$ : NSAID strategy). If these are unsuccessful, combinations of NSAIDs, acetaminophen, and caffeine can be tried. It has been shown that combination analgesics with acetaminophen-acetylsalicylic acid (ASA)-caffeine are superior in providing headache relief as compared to the ASA-acetaminophen combination without caffeine $(\mathrm{p}=0.0181)$, to ASA alone $(\mathrm{p}=0.0398)$, acetaminophen alone $(\mathrm{p}=0.0016)$, caffeine alone $(\mathrm{p}<0.0001)$, and placebo $(\mathrm{p}<0.0001) . .^{110}$ This combination analgesic is not available in Canada, but patients could be provided with $500 \mathrm{mg}$ of ASA, 500 $\mathrm{mg}$ of acetaminophen, and 50 to $100 \mathrm{mg}$ of caffeine to be taken simultaneously. Metoclopramide $10 \mathrm{mg}$ orally could be added as well. Even in patients with severe headache attacks, a fixed combination of ASA $500 \mathrm{mg}$, acetaminophen $400 \mathrm{mg}$, and caffeine $100 \mathrm{mg}$ was found to be efficacious as compared to placebo. ${ }^{111}$ Although caffeine might interfere with sleep if the patient needs to rest, it does seem to confer a definite benefit in analgesia when taken with analgesics like ASA or acetaminophen. In a major review of this subject, it was concluded that caffeine made a significant contribution to analgesia, and that to obtain the same amount of analgesia without caffeine required an increase of $40 \%$ in the dose of the other analgesics in the combination tablet. ${ }^{112}$ Combinations of ASA, acetaminophen, and caffeine taken together, with or without metoclopramide, can be considered for acute migraine treatment when simpler analgesic or NSAID regimens are not successful.

Many NSAIDs have been associated with an increased risk of cardiovascular events (myocardial infarction and stroke), and this may be a concern in patients with migraine and contraindications to triptans because of vascular disease. Even short-term use (<90 days) of ibuprofen, diclofenac and celecoxib appears to lead to an increased risk of serious coronary artery disease. Naproxen, on the other hand, does not appear to result in increased cardiovascular risk. ${ }^{113}$ Another study also concluded that naproxen had a relatively safe cardiovascular profile, in contrast to diclofenac which had a higher risk. ${ }^{114}$ The relevance of these studies on NSAIDs and cardiovascular risk to patients with migraine who may use these drugs only occasionally is unknown, but if effective, naproxen sodium might be considered the NSAID of choice in patients with cardiovascular disease.

For patients with contraindications to vasoconstrictors who do not respond to NSAIDs, acetaminophen, and combinations of these with caffeine, the options for acute migraine treatment are limited primarily to analgesic combinations containing opioids (including tramadol), unless another solution (e.g., dopamine antagonists) can be found. Occasional use of steroids (e.g., dexamethasone) may also be an option for some patients. The options for patients in the "vasoconstrictor- unresponsivecontraindicated strategy" are similar to the options discussed above for rescue medications under the "triptan-NSAID combination with recue medication strategy" (see Table 10). More caution with many of the available medications is needed, however, in that the patient using the "vasoconstrictorcontraindicated strategy" may be taking the medications on a regular basis, rather than only occasionally when their usual medication fails.

Although they are not recommended for routine use, in this circumstance combination analgesics containing codeine or tramadol may be necessary. In patients with severe attacks, stronger opioids and barbiturate-containing combination analgesics may also be a consideration in exceptional cases. The use of the opioid and barbiturate-containing analgesics should be very carefully monitored to avoid escalation of use and the development of medication overuse headache, dependence, abuse, and/or possible addiction. A headache diary which records medication use can be very helpful for this purpose.

As for all patients with migraine, whenever there is difficulty controlling migraine attacks satisfactorily with acute medications, non-pharmacological treatment approaches and pharmacological prophylactic drug therapy should be strongly considered. A multi-disciplinary treatment program may be helpful and should be pursued, if possible. ${ }^{115}$ 


\section{EXPERT CONSENSUS}

$i$. For patients with contraindications to vasoconstrictors or who have proven unresponsive to vasoconstrictors (triptans, DHE, and / or ergotamine), acetaminophen, NSAIDs (including ASA), acetaminophen-NSAID-caffeine combinations, dopamine antagonists (e.g., prochlorperazine), occasional steroid use, and opioidcontaining combination analgesics can be considered.

ii. Consideration needs to be given to the safety of NSAIDs in patients with cardiovascular disease. Because of a relatively benign cardiovascular profile, naproxen sodium may be the NSAID of choice, if effective, for patients with cardiovascular disease, particularly in patients who require relatively frequent $u$ se.

iii.If use of tramadol or codeine-containing combination analgesics is necessary, frequency of use should be carefully monitored and limited to use on 9 days a month or less.

iv. If, in exceptional cases, use of strong opioids or barbiturate-containing analgesics is considered, their frequency of use should be carefully monitored to avoid medication overuse headache, dependence, abuse, and possible addiction. Use should be limited to not more than seven days per month.

v. Behavioural treatment strategies and pharmacological prophylaxis may need to be maximized if a satisfactory pharmacological acute treatment cannot be established.

\section{Menstrual migraine strategy}

Women may have migraine attacks only at the time of menstruation (pure menstrual migraine), or they may have recurring attacks clearly related to menstruation but also have attacks during other parts of the menstrual cycle as well (menstrually related migraine). By definition, patients with menstrually related migraine (MRM) have migraine without aura attacks that occur during the time period starting two days before menstruation onset to three days after onset in at least two out of three menstrual cycles and additionally at other times of the cycle (Appendix A $1.1 \mathrm{http} / / /$ ihs-classification.org/en/02_ klassifikation/05_anhang/01.01.02_anhang.html).

It has long been a clinical impression that, at least in some women, MRM attacks are more severe and more difficult to treat than attacks occurring during other portions of the menstrual cycle. A recent study did to some extent confirm this clinical impression, in that MRM episodes were more impairing, longer lasting, and more likely to relapse than non-MRM episodes in a selected population of women with frequent menstrual migraine. ${ }^{116}$ Nevertheless, many studies have shown that MRM attacks appear to respond to triptans just as well as other migraine attacks do. A post hoc analysis of a major almotriptan trial, for example, found that almotriptan was similarly effective in relieving migraine symptoms and improving functional disability in MRM attacks as compared to non-MRM attacks. ${ }^{117}$ Many triptans have been shown to have good efficacy in treating MRM attacks. ${ }^{118-120}$

It may be that clinical trials such as those cited above excluded patients with particularly severe menstrual migraine through their inclusion / exclusion criteria. However, it does seem clear that the first step in the treatment of menstrual migraine attacks is to treat them in the same manner as other migraine attacks. If the response is less than optimal, treatment can be advanced to the use of triptan-naproxen sodium combinations. There is evidence that a sumatriptan-naproxen combination is efficacious in menstrual migraine. ${ }^{121}$ There is also evidence that adding dexamethasone $(4 \mathrm{mg})$ to rizatriptan $(10 \mathrm{mg}$ ) improves efficacy for menstrual migraine attacks above that of rizatriptan alone. ${ }^{82}$

Nevertheless, there are patients with severe MRM attacks who do not respond well to acute attack treatment with triptans. Some of these patients do not have a sufficient number of attacks per month to justify a daily prophylactic medication, or may not have responded to such medications. In these cases, short-term prophylaxis with a triptan around the period of headache vulnerability can provide benefit. Typically such regimens involve taking a triptan twice daily for six or seven days, starting two days prior to the anticipated onset of a menstrual migraine attack. Regular periods are essential for this mode of therapy to be effective. Efficacy for such a regimen has been shown for frovatriptan $2.5 \mathrm{mg}$ once or twice daily, naratriptan $1 \mathrm{mg}$ twice daily, and zolmitriptan $2.5 \mathrm{mg}$ twice or three times daily. ${ }^{122-125}$

Other options that have been researched for the short-term prophylactic treatment of problematic menstrual migraine include naproxen ${ }^{126}$, and percutaneous estrogen. Percutaneous estrogen has been used on the basis that it may blunt the large reduction in estrogen that occurs naturally at the onset of menstruation. An evidence-based review published in 2008 gave grade $\mathrm{B}$ recommendations for the perimenstrual use of transcutaneous estrogen $1.5 \mathrm{mg}$, frovatriptan $2.5 \mathrm{mg}$ twice daily, and naratriptan $1 \mathrm{mg}$ twice daily for the preventive treatment of MRM. ${ }^{120}$ However, recent controlled trials with estrogen have been plagued with post-dosing migraine attacks immediately after the estrogen treatment was stopped due to deferred estrogen withdrawal ${ }^{127}$, or have been unable to show a benefit (with $100 \mathrm{mcg}$ estradiol) over that provided by placebo. ${ }^{128}$ On balance, it would appear that the best option available for short-term monthly menstrual migraine prophylaxis is frovatriptan $2.5 \mathrm{mg}$ twice daily for at least six days. It has the best evidence, and among the triptans may be the preferred choice for short-term prophylaxis because of its long half-life (26 hours). Although medication overuse headache is a concern, taking an acute medication in a concentrated fashion over a short time period, with long medication free intervals during the remainder of the month may be less likely to lead to medication overuse headache than the same number of acute medication days spread more evenly throughout the month.

Other options for short term prophylaxis of MRM that have been evaluated by double-blind placebo controlled trials include magnesium pyrrolidone carboxylic acid $360 \mathrm{mg}$ daily started on the 15th day of the menstrual cycle and continued until menstruation started, and mefenamic acid $500 \mathrm{mg}$ three times daily started at the onset of the MRM and continued for the duration of menstrual bleeding. ${ }^{129,130}$ In an evidence-based review, because of the poor quality of these studies, it was concluded that there was insufficient evidence to recommend for or against using magnesium for short term prophylaxis of MRM. ${ }^{120}$ Given the nature of the mefenamic acid study, it was considered a symptomatic therapy study. The strength of 
evidence supporting its use was considered fair, and mefenamic acid was recommended for routine use. ${ }^{120}$

Continuous use of combined oral contraceptives (COCs) without interruption for a number of months in order to reduce the number of menstrual periods and, therefore, the number of MRM attacks has also been recommended. A detailed discussion on the use of extended COCs for menstrual migraine is beyond the scope of this guideline, and the evidence for efficacy in menstrual migraine is very limited. Several studies have shown that continuous use of low-dose COCs is safe for up to one year $^{131}$ and two years ${ }^{132}$, although these studies were conducted in the general population, and not specifically in women with migraine. Headache symptoms including those during the period of hormone withdrawal, although headache type was not determined, have also been reported to improve with continuous use of COCs in open label studies. ${ }^{133,134}$

Migraine with aura is a risk factor for stroke, and is often considered a contraindication to the use of COCs ${ }^{135}$, although it has been questioned whether currently used COCs with low estrogen dosage pose a risk. ${ }^{136} \mathrm{~A}$ recent review, however, concluded that use of low-dose COCs is associated with a twofold increased risk of ischemic stroke compared with nonusers, and that given the availability of other contraceptive methods; it is difficult to justify exposing women with migraine with aura to these risks solely for contraception. ${ }^{137}$ In otherwise healthy young females without other cardiovascular risk factors, however, the risks are small. In patients with disabling MRM, the risk/benefit ratio of using continuous low dose COCs for a period of time would need to be considered on a case by case basis. MRM migraine attacks are usually migraine without aura attacks.

It has been concluded that hormonal treatment of migraine is not a first-line strategy for most women with migraine, including menstrual migraine. ${ }^{135}$ While use of COCs for extended time periods without interruption may be helpful in selected women with refractory menstrual migraine, other treatment regimens should be tried first.

\section{EXPERT CONSENSUS}

$i$. In most patients, acute treatment of menstrual migraine attacks is similar to acute treatment of attacks occurring at other times during the menstrual cycle.

ii. For patients with refractory menstrual migraine who have a sufficient migraine attack frequency to justify general prophylactic therapy, this may be the best option.

iii. For selected patients with refractory menstrual migraine with predicable timing of menstrual cycles, short-term monthly prophylaxis can be considered. Among the available options (frovatriptan, zolmitriptan, naratriptan, and naproxen), frovatriptan $2.5 \mathrm{mg}$ twice a day starting two days before menstruation onset and continuing for six days has the strongest evidence for efficacy.

$i v$. In selected patients, hormonal manipulation including estrogen supplementation around the time of menstruation, and continuous use of combination oral contraceptives can be considered but other treatment options should be tried first. If continuous use of combined oral contraceptives is being considered, contraindications and cautions for these (e.g., smoking, migraine aura, etc) should be observed (see discussion with regard to migraine with aura above).

\section{Migraine during pregnancy strategy}

Medication use should be minimized during pregnancy, and use of behavioural approaches which have no potential side effects for the fetus should be maximized. Although there are no controlled drug trials indicating the level of safety of individual acute migraine medications, sufficient data exists to show that some of the drugs used for acute migraine therapy are relatively safe during pregnancy. In general, dosages and frequency of use during pregnancy should be kept as low as possible. Both patients and practitioners may find the "Motherisk" website helpful (http://www.motherisk.org/women/drugs.jsp) when there are questions about medication use during pregnancy. Further advice from Motherisk is available by telephone (416-813-6780).

\section{Acetaminophen}

Although no drug has been "proven" to be safe during pregnancy, through long experience acetaminophen is considered the safest of all acute migraine drugs and the analgesic of choice during pregnancy. Unfortunately, its efficacy in migraine is somewhat limited.

\section{Acetaminophen with codeine}

Acetaminophen with codeine is also considered relatively safe. The Australian and New Zealand College of Anaesthetists and Faculty of Pain Medicine have given codeine an " $\mathrm{A}$ " rating for use during pregnancy. An " $\mathrm{A}$ " rating is given to "drugs that have been taken by a large number of pregnant women and women of childbearing age without any proven increase in the frequency of malformations or other direct or indirect harmful effects on the fetus having been observed". ${ }^{138}$ It does need to be recognized, however, that prolonged high-dose use of codeine prior to delivery may produce codeine withdrawal symptoms in the neonate and is best avoided.

The relative safety of codeine use during pregnancy has recently been confirmed by data from the Norwegian Mother and Child Cohort Study. ${ }^{139}$ Pregnancy outcomes of 2,666 women who used codeine during pregnancy were compared with 65,316 women who used no opioids during pregnancy. No significant differences were found in the survival rate or the congenital malformation rate between codeine exposed and unexposed infants. Codeine use anytime during pregnancy was associated with planned Caesarean delivery (adjusted OR 1.4, 95\% CI 1.21.7; $\mathrm{p}<0.0001)$. Third-trimester use was associated with acute Caesarean delivery (adjusted OR 1.5, 95\% CI 1.3-1.8; $\mathrm{p}<0.0001$ ), and postpartum hemorrhage (adjusted OR 1.3, 95\% CI 1.1-1.5; $\mathrm{p}<0.0001)$. The authors concluded that no effects of maternal codeine intake during pregnancy were observed on infant survival or congenital malformation rate, but the association with acute Caesarean delivery and postpartum hemorrhage may justify caution when administering codeine toward the end of pregnancy. 


\section{Other opioids}

Other opioids have been given a "C" rating, which includes them among drugs that, owing to their pharmacological effects, have caused or may be suspected of causing harmful effects on the human fetus or neonate without causing malformations. These effects may be reversible, and in the case of the strong opioids include respiratory depression in the newborn infant and withdrawal symptoms in newborn infants after prolonged use. ${ }^{138}$

\section{ASA and other NSAIDs}

Acetylsalicylic acid (ASA) is best avoided during pregnancy, although it does not seem to cause malformations. When given late in pregnancy, it may cause premature closure of the fetal ductus arteriosus, and delay labour and birth. ASA increases the bleeding time both in the newborn infant and in the mother because of its irreversible antiplatelet effects. Products containing ASA should be avoided in the first trimester because of a possible increased risk of spontaneous abortion, and certainly during the last trimester for the reasons given above.

Other NSAIDs are preferable to ASA during pregnancy because of less prolonged effects on platelet function, but should also be avoided in the first trimester because of an increased risk of spontaneous abortion, and should be stopped before the 32nd week of gestation because of effects on the ductus arteriosus. During the latter part of pregnancy, they may also cause fetal renal impairment, inhibition of platelet aggregation and delayed labour and birth. ${ }^{138}$

\section{Ergotamines}

Ergotamines must be avoided during pregnancy due to uterotonic effects. ${ }^{95}$

\section{Triptans}

The role of the triptans during pregnancy remains controversial, but is becoming clarified as more data becomes available. Among the triptans, experience during pregnancy is by far the greatest with sumatriptan, and this is the triptan which should be used if triptan use is considered necessary. This might be the case, for example, in a patient with severe attacks that do not respond to acetaminophen or acetaminophen with codeine, especially if vomiting is present with the threat of dehydration. Data from the Norwegian Mother and Child Cohort Study has provided significant reassurance that sumatriptan is relatively safe during pregnancy. ${ }^{140}$ This was a large, observational, prospective cohort study which evaluated fetal outcomes following exposure to triptans during pregnancy. In this study, 1535 women who used triptans during pregnancy $(95 \%$ during the first trimester, and $65 \%$ during the second and third trimester) were compared with 375 migraine controls that had used triptans only prior to pregnancy, and to 68021 non-migraine controls that had never used triptans. Among the triptan users during pregnancy, approximately half had used sumatriptan, and the remainder had taken one of the others. No significant associations between triptan therapy during the first trimester and major congenital malformations or other adverse pregnancy outcomes were found. Triptan therapy during the second and/or third trimesters was, however, significantly associated with atonic uterus (adjusted OR: 1.4; 95\% CI 1.1-1.8), and blood loss $>500 \mathrm{~mL}$ during labor (adjusted OR: 1.3; 95\% CI 1.1-1.5).

The evidence from this study and from others suggests that sumatriptan is a relatively safe therapeutic option for the treatment of migraine attacks in pregnant women, but more studies are needed to confirm the safety of the other triptans in pregnancy. The practical application of these data is that women who suffer from migraine headaches which often render them unable to carry out tasks of daily living can use sumatriptan during pregnancy with relative safety, and without fear of harming their unborn baby. ${ }^{141}$

\section{Anti-emetics}

Several anti-emetics are considered safe during pregnancy. Metoclopramide would be considered the anti-emetic of choice. The Australian and New Zealand College of Anaesthetists and Faculty of Pain Medicine gives it an "A" rating, and also gives this rating to use of dimenhydrinate, and diphenhydramine during pregnancy. ${ }^{138}$ Domperidone is considered less safe, and was given a B2 rating (drugs that have been taken by only a limited number of pregnant women and women of child bearing age, but no malformations or other harmful effects on the fetus have been observed; and animal studies are inadequate for assessment of risk). Phenothiazines (e.g., prochlorperazine) are given a "C" rating, because when given in high doses during late pregnancy, phenothiazines have caused prolonged neurological disturbances in the infant. Drugs with a " $\mathrm{C}$ " rating are not known to cause fetal malformations. ${ }^{138}$

In summary, the application of all this information, some of it quite new, is summarized in the expert consensus statements below.

\section{EXPERT CONSENSUS}

i. Avoid use of medications during pregnancy if possible, especially during the first trimester, and consider use of non-pharmacologic strategies (e.g., trigger avoidance, relaxation exercises, etc).

ii. Acetaminophen is generally regarded as the safest analgesic for use during pregnancy.

iii. Alternatives to acetaminophen when acetaminophen is not adequate that may be considered for use during pregnancy include acetaminophen plus codeine combination products (intermittent use).

$i v$. Sumatriptan is also a potential option for acute migraine treatment in pregnancy, but is not recommended for routine use. There is significant evidence that the risks of sumatriptan use in pregnancy are minimal. It may be considered when migraine headaches are severe with significant disability and/or vomiting, other medications have failed during similar attacks, and the benefits appear to outweigh potential risks. There is much less information available regarding the safety of the other triptans during pregnancy; therefore, they should be avoided.

v. NSAIDs (e.g., ibuprofen, naproxen sodium) should be used with caution during pregnancy (possible increased risk of spontaneous abortion in first trimester), and should be discontinued before week 32 . 
vi. Because of the long-lasting effects of ASA on platelet function, other NSAIDs are preferred to ASA for use during pregnancy.

vii.Metoclopramide has not been associated with birth defects, and may be used during pregnancy. Dimenhydrinate is considered relatively safe for use as an antiemetic during pregnancy (but there is no controlled trial evidence for efficacy in migraine). Domperidone should be avoided, as there is a lack of data with regard to its use during pregnancy.

viii.Ergot alkaloids are contraindicated during pregnancy.

\section{Migraine during lactation strategy}

Maternal plasma levels, which are dose dependant, are an important determinant of drug levels in breast milk. High lipid solubility, low molecular weight, low protein binding and the unionised state all favour secretion into breast milk.

\section{Acetaminophen}

Acetaminophen is considered safe, as there have been no reports of adverse effects, and levels in breast milk are a fraction of the recommended neonatal doses. ${ }^{138}$

\section{ASA and other NSAIDs}

Acetylsalicylic acid in analgesic doses for the mother are not considered safe, as salicylates are eliminated slowly by the neonate, cause platelet dysfunction, and have been associated with Reye's syndrome.

Among other NSAIDs, ibuprofen is preferred as it has a low transfer rate into breast milk, is short-acting, is free of active metabolites, and has the best documented safety. Short-term or occasional use of diclofenac and ketorolac is considered compatible with breast feeding. The safety of naproxen is less clear, but it is also considered compatible with breast feeding. ${ }^{138}$

\section{Triptans}

Data on triptans and breastfeeding is scarce, but the infant dose after maternal ingestion of sumatriptan would appear to be small. The American Academy of Pediatrics has considered maternal sumatriptan use to be compatible with breast feeding. ${ }^{142}$

\section{Opioids}

The short-term use of opioids is generally considered relatively safe during lactation as most opioids are secreted into breast milk in low doses, but they should be used with caution, especially if the infant is premature or less than four weeks old. The infant should be monitored for sedation and other adverse effects including episodes of cyanosis. Morphine has been considered the opioid of choice if potent analgesia is required in breastfeeding mothers. Although it is transferred into breast milk, the oral availability in the infant is low (about 25\%). Although codeine is generally considered safe, infant toxicity and death has been reported in a breastfed neonate whose mother was an ultra-fast metabolizer of codeine. ${ }^{138}$ In mothers who are breastfeeding, avoiding codeine for long-term therapy seems reasonable as it has a highly variable metabolism, and has been associated with one reported death and multiple cases of toxicity in nursing infants. Five to forty percent of individuals, depending on ethnic background, have duplications of the CYP2D6 gene and, therefore, are ultra-rapid metabolizers of codeine. These patients may produce more morphine than is predicted when treated with codeine, and the morphine may in turn enter the breast milk. If opioid therapy is necessary during breastfeeding, there are better alternatives. Infant toxicity from maternal morphine use during breastfeeding has not been reported. ${ }^{143}$ If nursing mothers are taking opioids, the breast milk should be discarded if the mother experiences significant sedation. The majority of adverse events occurred in very young infants in the first month of life, so particular caution should be exercised during this time period.

\section{Anti-emetics}

Metoclopramide, domperidone, dimenhydrinate, and prochlorperazine are all considered safe in breastfeeding. ${ }^{138}$

\section{EXPERT CONSENSUS}

i. Acetaminophen is considered safe during lactation.

ii. Ibuprofen is the NSAID of choice during breast feeding. Diclofenac, ketorolac, and naproxen are also considered compatible with breast feeding, but with less data. ASA should be avoided.

iii. Sumatriptan is considered compatible with breast feeding. iv. Metoclopramide, domperidone, dimenhydrinate, and prochlorperazine are all considered safe in breastfeeding.

$v$. If pain medication is necessary in a breastfeeding mother, the safest drugs are acetaminophen and the NSAIDs. If opioids are considered necessary:

a. Morphine is considered the opioid of choice if potent analgesia is required in breastfeeding mothers.

$b$. Codeine in occasional doses is considered generally safe, although serious toxicity has been reported in maternal ultra-fast metabolizers (caution if premature infant or neonate less than four weeks old).

c. Avoid codeine for long-term therapy because of its variable maternal metabolism, because multiple cases of neonatal toxicity have been reported, and more effective opioid choices are available.

d. Avoid high doses of opioids in breastfeeding women. e. For all opioids, exercise particular caution if the breastfeeding infant is under one month old.

\section{Premonitory Symptoms and Migraine Treatment}

Premonitory symptoms precede the other symptoms of the migraine attack by 2 to 48 hours. They occur before the aura in migraine with aura, and before the onset of pain in migraine without aura. ${ }^{144}$ Many different premonitory symptoms have been reported by patients with migraine including fatigue, mood changes, and gastrointestinal symptoms. ${ }^{145-147}$ Depending on how the data is collected, between 33 and $80 \%$ of migraine sufferers in clinic-based patient samples report premonitory symptoms. ${ }^{145,146}$ In selected patient populations it has been found that patients are able to predict with reasonable accuracy whether a symptom they experience as a possible premonitory symptom is likely to be followed by a migraine headache or not. ${ }^{148}$ In summary, it would appear that a significant number of patients 
with migraine have premonitory symptoms; many have at least several hours of warning before their headache attack starts, and for an uncertain minority of these patients the premonitory symptoms are reasonably reliable predictors of the oncoming attack.

Much more research is needed before firm recommendations can be made regarding therapy of migraine attacks by giving acute medications during the premonitory phase. Several clinical trials have been done in highly selected patient populations, and have led to the following conclusions: ${ }^{149-151}$

1. Naratriptan $2.5 \mathrm{mg}$ can prevent some migraine attacks when taken during the premonitory period (open label evidence).

2. Domperidone $30-40 \mathrm{mg}$ can prevent some migraine attacks when taken during the premonitory period (doubleblind placebo-controlled cross-over evidence)

3. Both drugs appear to work better when taken early (at least two hours) before headache onset.

Warnings have recently been issued regarding domperidone doses of this magnitude and cardiac arrhythmias (Health Canada Endorsed Important Safety Information on Domperidone Maleate, March 2, 2012), so use of domperidone in this context may be problematic. With regard to triptan use, if the premonitory period represents a time of heightened migraine vulnerability, analogous to what occurs just prior to menstruation in women with menstrual migraine, it might be logical to use a triptan with a relatively long half-life, like frovatriptan, during the premonitory period in selected patients, but more evidence is needed. ${ }^{152}$

\section{EXPERT CONSENSUS}

$i$. There is insufficient evidence to make recommendations regarding the treatment of migraine during the premonitory period. In selected patients with clear cut and reliable premonitory symptoms, a trial of a triptan with a long half-life (e.g., frovatriptan) in a pre-emptive fashion could be considered.

\section{Conclusion ANd Summary}

Pharmacological acute migraine treatment is complex, and the treatment strategies discussed above may be helpful to practitioners when considering which treatment to recommend for a specific patient. Tables $11 \mathrm{~A}$ and $11 \mathrm{~B}$ summarize the treatment strategies and the component medications of each strategy. As with all pharmacological therapies, evidence for efficacy, side effects, and contraindications need to be considered. An additional consideration in acute migraine pharmacological treatment is the potential complication of medication overuse headache, which may complicate the use of any acute medication for migraine attacks (with the exception of dopamine antagonists and possibly dihydroergotamine) when they are used beyond the recommended days per month.

Table 11A: Acute migraine treatment strategies and medication summary: General Strategies

\begin{tabular}{|c|c|c|c|}
\hline \multirow{21}{*}{$\begin{array}{l}\text { Increasing } \\
\text { migraine severity - } \\
\text { Refractoriness to therapy }\end{array}$} & Clinical Phenotype & Strategy & Medications \\
\hline & \multirow{2}{*}{$\begin{array}{l}\text { Mild - moderate attack } \\
\text { strategies }\end{array}$} & 1.a Acetaminophen & Acetaminophen \pm metoclopramide \\
\hline & & 1.b NSAID & $\begin{array}{l}\text { Ibuprofen, diclofenac potassium, naproxen } \\
\text { sodium, ASA, all } \pm \text { metoclopramide }\end{array}$ \\
\hline & \multirow{9}{*}{$\begin{array}{l}\text { Moderate - severe } \\
\text { attack /NSAID failure } \\
\text { strategies }\end{array}$} & $\begin{array}{l}\text { 2.a NSAID with triptan } \\
\text { rescue }\end{array}$ & $\begin{array}{l}\text { NSAID } \pm \text { metoclopramide }+ \text { a triptan later for } \\
\text { rescue if necessary }\end{array}$ \\
\hline & & 2.b Triptan & Triptan \pm metoclopramide \\
\hline & & & Sumatriptan (SC injection, nasal, oral) \\
\hline & & & Zolmitriptan (nasal, oral, wafer) \\
\hline & & & Rizatriptan (oral, wafer) \\
\hline & & & Naratriptan (oral) \\
\hline & & & Eletriptan (oral) \\
\hline & & & Almotriptan (oral) \\
\hline & & & Frovatriptan (oral) \\
\hline & \multirow{9}{*}{$\begin{array}{l}\text { Refractory migraine } \\
\text { strategies }\end{array}$} & $\begin{array}{l}\text { 3.a Triptan - NSAID } \\
\text { combination }\end{array}$ & $\begin{array}{l}\text { Triptan + NSAID taken simultaneously } \pm \\
\text { metoclopramide }\end{array}$ \\
\hline & & $\begin{array}{l}\text { 3.b Triptan - NSAID } \\
\text { combination with } \\
\text { rescue }\end{array}$ & $\begin{array}{l}\text { Triptan + NSAID taken simultaneously } \pm \\
\text { metoclopramide }+ \text { one or more for rescue later (as } \\
\text { necessary) of: }\end{array}$ \\
\hline & & & Ketorolac IM \\
\hline & & & Indomethacin (oral or rectal) \\
\hline & & & Prochlorperazine (oral or rectal) \\
\hline & & & Chlorpromazine (oral) \\
\hline & & & Dexamethasone or prednisone \\
\hline & & & Opioid combination analgesic \\
\hline & & 3.c Dihydroergotamine & $\begin{array}{l}\text { Dihydroergotamine (nasal or SC or IM self- } \\
\text { injection) } \pm \text { metoclopramide }\end{array}$ \\
\hline
\end{tabular}


Table 11B: Acute migraine treatment strategies and medication summary: Special Strategies

\begin{tabular}{|c|c|}
\hline Clinical phenotype / strategy & Medication options \\
\hline $\begin{array}{l}\text { Vasoconstrictor unresponsive } \\
\text { or contraindicated } \\
\text { strategy }\end{array}$ & $\begin{array}{l}\text { 1. One of: acetaminophen, ibuprofen, diclofenac potassium, naproxen sodium, or ASA, all } \pm \\
\text { metoclopramide } \\
\text { 2. Combinations of acetaminophen, ASA, and caffeine (note: combination product not available in } \\
\text { Canada but can use individual components) } \pm \text { metoclopramide } \\
\text { 3. One or more of: } \\
\\
>\text { ketorolac IM (self-injection) } \\
>\text { indomethacin (oral or rectal) } \\
>\text { chlorpromazine (oral) } \\
>\text { opioid (including tramadol) combination analgesics (monitor use closely) } \\
\text { 4. One of: butalbital-containing analgesics, or butorphanol nasal spray (both: exceptional } \\
\text { circumstances only - monitor use closely) }\end{array}$ \\
\hline Menstrual migraine strategy & $\begin{array}{l}\text { 1. Acute therapy: General strategies } 1 \text { through } 3 \mathrm{c} \\
\text { 2. Short term prophylaxis with one of: frovatriptan, zolmitriptan, naratriptan, or naproxen } \\
\text { (frovatriptan recommended) } \\
\text { 3. Short term prophylaxis with percutaneous estrogen } \\
\text { 4. Continuous oral contraceptives (observe contraindications) } \\
\text { 5. Less proven options for short term prophylaxis: magnesium, mefenamic acid }\end{array}$ \\
\hline $\begin{array}{l}\text { Migraine } \\
\text { strategy }\end{array}$ & $\begin{array}{l}\text { Avoid medication where possible } \\
\text { 1. acetaminophen } \pm \text { metoclopramide } \\
\text { 2. acetaminophen with codeine } \pm \text { metoclopramide } \\
\left.\text { 3. ibuprofen (avoid } 1^{\text {st }} \text { trimester and at /after } 32^{\text {nd }} \text { week gestation }\right) \pm \text { metoclopramide } \\
\text { 4. sumatriptan (if benefits outweigh risks }- \text { limited data but relatively safe } \pm \text { metoclopramide }\end{array}$ \\
\hline $\begin{array}{l}\text { Migraine during lactation } \\
\text { strategy }\end{array}$ & $\begin{array}{l}\text { Avoid medication where possible } \\
\text { 1. acetaminophen } \pm \text { metoclopramide } \\
\text { 2. ibuprofen } \pm \text { metoclopramide } \\
\text { 3. sumatriptan } \pm \text { metoclopramide } \\
\text { 4. morphine (exceptional circumstances only - avoid high doses, maternal sedation, avoid when } \\
\text { infant is premature, and use caution if infant under } 1 \text { month of age) }\end{array}$ \\
\hline
\end{tabular}

\section{REFERENCES}

1. Lipton RB, Stewart WF, Stone AM, Lainez MJ, Sawyer JP, Disability in Strategies of Care Study,group. Stratified care vs step care strategies for migraine: the Disability in Strategies of Care (DISC) Study: A randomized trial.[see comment]. JAMA. 2000;284:2599-605.

2. Lipton RB, Baggish JS, Stewart WF, Codispoti JR, Fu M. Efficacy and safety of acetaminophen in the treatment of migraine: results of a randomized, double-blind, placebo-controlled, populationbased study. Arch Intern Med. 2000;160:3486-92.

3. Prior MJ, Codispoti JR, Fu M. A randomized, placebo-controlled trial of acetaminophen for treatment of migraine headache. Headache. 2010;50:819-33.

4. Hamalainen ML, Hoppu K, Valkeila E, Santavuori P. Ibuprofen or acetaminophen for the acute treatment of migraine in children: a double-blind, randomized, placebo-controlled, crossover study. Neurology. 1997;48:103-7.

5. Larsen BH, Christiansen LV, Andersen B, Olesen J. Randomized double-blind comparison of tolfenamic acid and paracetamol in migraine. Acta Neurol Scand. 1990;81:464-7.

6. Ottani A, Leone S, Sandrini M, Ferrari A, Bertolini A. The analgesic activity of paracetamol is prevented by the blockade of cannabinoid CB1 receptors. Eur J Pharmacol. 2006;531:280-1.

7. Cooke LJ, Becker WJ. Migraine prevalence, treatment and impact: the canadian women and migraine study. Can J Neurol Sci. 2010; 37:580-7.
8. Suthisisang C, Poolsup N, Kittikulsuth W, Pudchakan P, Wiwatpanich P. Efficacy of low-dose ibuprofen in acute migraine treatment: systematic review and meta-analysis. Ann Pharmacother. 2007;41:1782-91.

9. Rabbie R, Derry S, Moore RA, McQuay HJ. Ibuprofen with or without an antiemetic for acute migraine headaches in adults. Cochrane Database Syst Rev. 2010;008039.

10. Diener HC, Bussone $\mathrm{G}$, de Liano $\mathrm{H}$, et al. Placebo-controlled comparison of effervescent acetylsalicylic acid, sumatriptan and ibuprofen in the treatment of migraine attacks. Cephalalgia. 2004;24:947-54.

11. Suthisisang C, Poolsup N, Suksomboon N, Lertpipopmetha V, Tepwitukgid B. Meta-analysis of the efficacy and safety of naproxen sodium in the acute treatment of migraine. Headache. 2010;50:808-18.

12. Derry S, Rabbie R, Moore RA. Diclofenac with or without an antiemetic for acute migraine headaches in adults. Cochrane Database Syst Rev. 2012;2:008783.

13. Diener HC, Montagna P, Gacs G, et al. Efficacy and tolerability of diclofenac potassium sachets in migraine: a randomized, doubleblind, cross-over study in comparison with diclofenac potassium tablets and placebo. Cephalalgia. 2006;26:537-47.

14. Kirthi V, Derry S, Moore RA, McQuay HJ. Aspirin with or without an antiemetic for acute migraine headaches in adults. Cochrane Database Syst Rev. 2010;4:008041.

15. Lampl C, Voelker M, Diener HC. Efficacy and safety of $1,000 \mathrm{mg}$ effervescent aspirin: individual patient data meta-analysis of 
three trials in migraine headache and migraine accompanying symptoms. J Neurol. 2007;254:705-12.

16. Shields KG, Goadsby PJ. Serotonin receptors modulate trigeminovascular responses in ventroposteromedial nucleus of thalamus: a migraine target? Neurobiol Dis. 2006;23:491-501.

17. Loder E. Triptan therapy in migraine. N Engl J Med. 2010;363: 63-70.

18. Goldstein DJ, Roon KI, Offen WW, et al. Selective seratonin 1F (5HT(1F)) receptor agonist LY334370 for acute migraine: a randomised controlled trial. Lancet. 2001;358:1230-4.

19. Ferrari MD, Goadsby PJ, Roon KI, Lipton RB. Triptans (serotonin, 5-HT1B/1D agonists) in migraine: detailed results and methods of a meta-analysis of 53 trials. [see comment][erratum appears in Cephalalgia. 2003 Feb;23(1):71.]. Cephalalgia. 2002;22:633-58.

20. Cady RK, Freitag FG, Mathew NT, et al. Allodynia-associated symptoms, pain intensity and time to treatment: predicting treatment response in acute migraine intervention. Headache. 2009;49:350-63

21. Bigal ME, Serrano D, Buse D, Scher A, Stewart WF, Lipton RB. Acute migraine medications and evolution from episodic to chronic migraine: a longitudinal population-based study. Headache. 2008;48:1157-68.

22. Anonymous Treatment of migraine attacks with sumatriptan. The Subcutaneous Sumatriptan International Study Group. N Engl J Med. 1991;325:316-21.

23. Gawel MJ, Worthington I, Maggisano A. A systematic review of the use of triptans in acute migraine.[see comment]. [Review] [74 refs]. Can J Neurol Sci. 2001;28:30-41.

24. Tfelt-Hansen P, De Vries P, Saxena PR. Triptans in migraine: a comparative review of pharmacology, pharmacokinetics and efficacy. Drugs. 2000;60:1259-87.

25. Gladstone JP, Gawel M. Newer formulations of the triptans: advances in migraine management. [Review] [116 refs]. Drugs. 2003;63:2285-305

26. Rapoport AM, Tepper SJ, Bigal ME, Sheftell FD. The triptan formulations : how to match patients and products. [Review] [75 refs]. CNS Drugs. 2003;17:431-47.

27. Dodick DW, Lipton RB, Ferrari MD, et al. Prioritizing treatment attributes and their impact on selecting an oral triptan: results from the TRIPSTAR Project. [Review] [41 refs]. Curr Pain Headache Rep. 2004;8:435-42.

28. Ferrari MD. Current perspectives on effective migraine treatments: are small clinical differences important for patients? [Review] [9 refs]. Med Actual. 2003;39:37-41.

29. Gawel M, Aschoff J, May A, Charlesworth BR, REALIZE Study T. Zolmitriptan $5 \mathrm{mg}$ nasal spray: efficacy and onset of action in the acute treatment of migraine--results from phase 1 of the REALIZE Study. Headache. 2005;45:7-16.

30. Tfelt-Hansen P. Sumatriptan for the treatment of migraine attacks-a review of controlled clinical trials. Cephalalgia. 1993;13: $238-44$.

31. Dodick D, Brandes J, Elkind A, Mathew N, Rodichok L. Speed of onset, efficacy and tolerability of zolmitriptan nasal spray in the acute treatment of migraine: a randomised, double-blind, placebo-controlled study. CNS Drugs. 2005;19:125-36.

32. Dodick DW, Sandrini G, Williams P. Use of the sustained pain-free plus no adverse events endpoint in clinical trials of triptans in acute migraine. CNS Drugs. 2007;21:73-82

33. Dodick D, Lipton RB, Martin V, et al. Consensus statement: cardiovascular safety profile of triptans (5-HT agonists) in the acute treatment of migraine. [Review] [66 refs]. Headache. 2004; 44:414-25.

34. Modgill G, Jette N, Wang JL, Becker WJ, Patten SB. A populationbased longitudinal community study of major depression and migraine. Headache. 2012;52:422-32.

35. Jelinski SE, Magnusson JE, Becker WJ, CHORD Study G. Factors associated with depression in patients referred to headache specialists. Neurology. 2007;68:489-95.

36. Wenzel RG, Tepper S, Korab WE, Freitag F. Serotonin syndrome risks when combining SSRI/SNRI drugs and triptans: is the FDA's alert warranted? Ann Pharmacother. 2008;42:1692-6.
37. Evans RW, Tepper SJ, Shapiro RE, Sun-Edelstein C, Tietjen GE. The FDA alert on serotonin syndrome with use of triptans combined with selective serotonin reuptake inhibitors or selective serotonin-norepinephrine reuptake inhibitors: American Headache Society position paper. Headache. 2010;50: 1089-99.

38. Soldin OP, Tonning JM; Obstetric-Fetal Pharmacology Research Unit Network. Serotonin syndrome associated with triptan monotherapy. N Engl J Med. 2008 May 15;358(20):2185-6.

39. Headache Classification Subcommittee of the International Headache,Society. The International Classification of Headache Disorders: 2nd edition. Cephalalgia. 2004;24:9-160.

40. Yates R, Sorensen J, Bergstrom M, et al. Distribution of intranasal C-zolmitriptan assessed by positron emission tomography. Cephalalgia. 2005;25:1103-9.

41. Charlesworth BR, Dowson AJ, Purdy A, Becker WJ, Boes-Hansen $\mathrm{S}$, Farkkila M. Speed of onset and efficacy of zolmitriptan nasal spray in the acute treatment of migraine: a randomised, doubleblind, placebo-controlled, dose-ranging study versus zolmitriptan tablet. CNS Drugs. 2003;17:653-67.

42. Ahrens SP, Farmer MV, Williams DL, et al. Efficacy and safety of rizatriptan wafer for the acute treatment of migraine. Rizatriptan Wafer Protocol 049 Study Group. Cephalalgia. 1999;19:525-30.

43. Aurora S, Kori S, Barrodale P, Nelsen A, McDonald S. Gastric stasis occurs in spontaneous, visually induced, and interictal migraine. Headache. 2007;47:1443-6.

44. Aurora SK, Kori SH, Barrodale P, McDonald SA, Haseley D. Gastric stasis in migraine: more than just a paroxysmal abnormality during a migraine attack. Headache. 2006;46:57-63.

45. Johannes CB, Varas-Lorenzo C, McQuay LJ, Midkiff KD, Fife D. Risk of serious ventricular arrhythmia and sudden cardiac death in a cohort of users of domperidone: a nested case-control study. Pharmacoepidemiol Drug Saf. 2010;19:881-8.

46. van Noord C, Dieleman JP, van Herpen G, Verhamme K, Sturkenboom MC. Domperidone and ventricular arrhythmia or sudden cardiac death: a population-based case-control study in the Netherlands. Drug Safety. 2010;33:1003-14.

47. Tokola RA. The effect of metoclopramide and prochlorperazine on the absorption of effervescent paracetamol in migraine. Cephalalgia. 1988;8:139-47.

48. Tokola RA, Neuvonen PJ. Effects of migraine attack and metoclopramide on the absorption of tolfenamic acid. Br J Clin Pharmacol. 1984;17:67-75.

49. Volans GN. The effect of metoclopramide on the absorption of effervescent aspirin in migraine. Br J Clin Pharmacol. 1975;2: 57-63.

50. MacGregor EA, Wilkinson M, Bancroft K. Domperidone plus paracetamol in the treatment of migraine. Cephalalgia. 1993;13: 124-7.

51. Schulman EA, Dermott KF. Sumatriptan plus metoclopramide in triptan-nonresponsive migraineurs. [see comment]. Headache. 2003;43:729-33

52. Ferrari MD, James MH, Bates D, et al. Oral sumatriptan: effect of a second dose, and incidence and treatment of headache recurrences. Cephalalgia. 1994;14:330-8.

53. Brandes JL, Kudrow D, Stark SR, et al. Sumatriptan-naproxen for acute treatment of migraine: a randomized trial. JAMA. 2007; 297:1443-54.

54. Geraud G, Keywood C, Senard JM. Migraine headache recurrence: relationship to clinical, pharmacological, and pharmacokinetic properties of triptans. Headache. 2003;43:376-88.

55. Winner P, Ricalde O, Le Force B, Saper J, Margul B. A double-blind study of subcutaneous dihydroergotamine vs subcutaneous sumatriptan in the treatment of acute migraine. [see comment]. Arch Neurol. 1996;53:180-4.

56. Teall J, Tuchman M, Cutler N, et al. Rizatriptan (MAXALT) for the acute treatment of migraine and migraine recurrence. A placebocontrolled, outpatient study. Rizatriptan 022 Study Group. Headache. 1998;38:281-7.

57. Tepper SJ, Donnan GA, Dowson AJ, et al. A long-term study to maximise migraine relief with zolmitriptan. Curr Med Res Opin. $1999 ; 15: 254-71$ 
58. Sheftell F, Ryan R, Pitman V, Eletriptan Steering C. Efficacy, safety, and tolerability of oral eletriptan for treatment of acute migraine: a multicenter, double-blind, placebo-controlled study conducted in the United States. Headache. 2003;43:202-13.

59. Rapoport AM, Ramadan NM, Adelman JU, et al. Optimizing the dose of zolmitriptan (Zomig, 311C90) for the acute treatment of migraine. A multicenter, double-blind, placebo-controlled, dose range-finding study. The 017 Clinical Trial Study Group. Neurology. 1997;49:1210-8.

60. Bates D, Ashford E, Dawson R, et al. Subcutaneous sumatriptan during the migraine aura. Sumatriptan Aura Study Group. Neurology. 1994;44:1587-92.

61. Olesen J, Diener HC, Schoenen J, Hettiarachchi J. No effect of eletriptan administration during the aura phase of migraine. Eur J Neurol. 2004;11:671-7.

62. Dowson A. Can oral 311C90, a novel 5-HT1D agonist, prevent migraine headache when taken during an aura? Eur Neurol. 1996;36:28-31.

63. Aurora SK, Barrodale PM, McDonald SA, Jakubowski M, Burstein $\mathrm{R}$. Revisiting the efficacy of sumatriptan therapy during the aura phase of migraine. Headache. 2009;49:1001-4.

64. Artto V, Nissila M, Wessman M, Palotie A, Farkkila M, Kallela M. Treatment of hemiplegic migraine with triptans. Eur J Neurol. 2007;14:1053-6.

65. Klapper J, Mathew N, Nett R. Triptans in the treatment of basilar migraine and migraine with prolonged aura. Headache. 2001;41: 981-4

66. Brandes JL, Kudrow D, Stark SR, et al. Sumatriptan-naproxen for acute treatment of migraine: a randomized trial. JAMA. 2007; 297:1443-54

67. Smith TR, Sunshine A, Stark SR, Littlefield DE, Spruill SE, Alexander WJ. Sumatriptan and naproxen sodium for the acute treatment of migraine. Headache. 2005;45:983-91.

68. Mathew NT, Landy S, Stark S, et al. Fixed-dose sumatriptan and naproxen in poor responders to triptans with a short half-life. Headache. 2009;49:971-82.

69. Silberstein SD, Mannix LK, Goldstein J, et al. Multimechanistic (sumatriptan-naproxen) early intervention for the acute treatment of migraine. Neurology. 2008;71:114-21.

70. Krymchantowski AV. Naproxen sodium decreases migraine recurrence when administered with sumatriptan. Arq Neuropsiquiatr. 2000;58:428-30.

71. Jakubowski M, Levy D, Goor-Aryeh I, Collins B, Bajwa Z, Burstein R. Terminating migraine with allodynia and ongoing central sensitization using parenteral administration of COX1/COX2 inhibitors. Headache. 2005;45:850-61.

72. Kelley NE, Tepper DE. Rescue therapy for acute migraine, part 3: opioids, NSAIDs, steroids, and post-discharge medications. Headache. 2012;52:467-82

73. Turkewitz LJ, Casaly JS, Dawson GA, Wirth O, Hurst RJ, Gillette PL. Self-administration of parenteral ketorolac tromethamine for head pain. Headache. 1992;32:452-4.

74. Sandrini G, Cerbo R, Del Bene E, et al. Efficacy of dosing and redosing of two oral fixed combinations of indomethacin, prochlorperazine and caffeine compared with oral sumatriptan in the acute treatment of multiple migraine attacks: a double-blind, double-dummy, randomised, parallel group, multicentre study. Int J Clin Pract. 2007;61:1256-69.

75. Di Monda V, Nicolodi M, Aloisio A, et al. Efficacy of a fixed combination of indomethacin, prochlorperazine, and caffeine versus sumatriptan in acute treatment of multiple migraine attacks: a multicenter, randomized, crossover trial. Headache. 2003;43:835-44

76. Kelley NE, Tepper DE. Rescue therapy for acute migraine, part 2 : neuroleptics, antihistamines, and others. Headache. 2012;52: 292-306.

77. Jones EB, Gonzalez ER, Boggs JG, Grillo JA, Elswick RK,Jr. Safety and efficacy of rectal prochlorperazine for the treatment of migraine in the emergency department. Ann Emerg Med. 1994;24:237-41.

78. McEwen JI, O'Connor HM, Dinsdale HB. Treatment of migraine with intramuscular chlorpromazine. Ann Emerg Med. 1987;16: $758-63$
79. Rozen TD. Migraine headache: immunosuppressant therapy. Curr Treat Options Neurol. 2002;4:395-401.

80. Colman I, Friedman BW, Brown MD, et al. Parenteral dexamethasone for acute severe migraine headache: metaanalysis of randomised controlled trials for preventing recurrence. BMJ. 2008;336:1359-61.

81. Taheraghdam AA, Amiri H, Shojaan H, Shamsvahdati S, Houshyar Y. Intravenous dexamethasone versus morphine in relieving of acute migraine headache. Pak J Biol Sci. 2011;14:682-7.

82. Bigal M, Sheftell F, Tepper S, Tepper D, Ho TW, Rapoport A. A randomized double-blind study comparing rizatriptan, dexamethasone, and the combination of both in the acute treatment of menstrually related migraine. Headache. 2008;48: 1286-93.

83. Boureau F, Joubert JM, Lasserre V, Prum B, Delecoeuillerie G. Double-blind comparison of an acetaminophen $400 \mathrm{mg}$-codeine $25 \mathrm{mg}$ combination versus aspirin $1000 \mathrm{mg}$ and placebo in acute migraine attack. Cephalalgia. 1994;14:156-61.

84. Ho TW, Rodgers A, Bigal ME. Impact of recent prior opioid use on rizatriptan efficacy. A post hoc pooled analysis. Headache. 2009; 49:395-403

85. Bigal ME, Lipton RB. Excessive acute migraine medication use and migraine progression. Neurology. 2008;71:1821-8.

86. De Felice M, Porreca F. Opiate-induced persistent pronociceptive trigeminal neural adaptations: potential relevance to opiateinduced medication overuse headache. Cephalalgia. 2009;29: 1277-84.

87. Madadi P, Koren G. Pharmacogenetic insights into codeine analgesia: implications to pediatric codeine use. Pharmacogenomics. 2008;9:1267-84.

88. Grond S, Sablotzki A. Clinical pharmacology of tramadol. Clin Pharmacokinet. 2004;43:879-923.

89. Tepper SJ. Medication-overuse headache. CONTINUUM: Lifelong Learning in Neurology. 2012;18:807-22.

90. Fisher MA, Glass S. Butorphanol (Stadol): a study in problems of current drug information and control. Neurology. 1997;48: 1156-60.

91. Bigal ME, Lipton RB. Acute treatment of migraine headache. Curr Treat Options Neurol. 2003;5:423-30.

92. Gerhardt RT, Hermstad E, Crawford DM, Rayfield J, Pfaff J, Hunter CJ. Postdischarge secobarbital after ED migraine treatment decreases pain and improves resolution. Am J Emerg Med. 2011; 29:86-90

93. Silberstein SD, McCrory DC. Ergotamine and dihydroergotamine: history, pharmacology, and efficacy. Headache. 2003;43:144-66.

94. Lipton RB. Ergotamine tartrate and dihydroergotamine mesylate: safety profiles. Headache. 1997;37:S33-41.

95. Tfelt-Hansen P, Saxena PR, Dahlof C, et al. Ergotamine in the acute treatment of migraine: a review and European consensus. [Review] [84 refs]. Brain. 2000;123:9-18.

96. Baron EP, Tepper SJ. Revisiting the role of ergots in the treatment of migraine and headache. Headache. 2010;50:1353-61.

97. Bigal ME, Tepper SJ. Ergotamine and dihydroergotamine: a review. Curr Pain Headache Rep. 2003;7:55-62.

98. MaassenVanDenBrink A, Reekers M, Bax WA, Ferrari MD, Saxena PR. Coronary side-effect potential of current and prospective antimigraine drugs. Circulation. 1998;98:25-30.

99. Hoskin KL, Kaube H, Goadsby PJ. Central activation of the trigeminovascular pathway in the cat is inhibited by dihydroergotamine. A c-Fos and electrophysiological study. Brain. 1996;119:249-56.

100. Becker WJ, Riess CM, Hoag J. Effectiveness of subcutaneous dihydroergotamine by home injection for migraine. Headache. 1996;36:144-8.

101. Weisz MA, el-Raheb M, Blumenthal HJ. Home administration of intramuscular DHE for the treatment of acute migraine headache. Headache. 1994:34:371-3.

102.Klapper JA, Stanton J. Clinical experience with patient administered subcutaneous dihydroergotamine mesylate in refractory headaches. Headache. 1992;32:21-3.

103. Rothrock JF. Patient information regarding subcutaneous selfadministration of dihydroergotamine (DHE). Headache. 2007; 47:740. 
104. Raskin NH. Repetitive intravenous dihydroergotamine as therapy for intractable migraine. Neurology. 1986;36:995-7.

105. Silberstein SD, Schulman EA, Hopkins MM. Repetitive intravenous DHE in the treatment of refractory headache. Headache. 1990;30:334-9.

106.Eadie MJ. Ergot of rye-the first specific for migraine. J Clin Neurosci. 2004;11:4-7.

107. Schmidt R, Fanchamps A. Effect of caffeine on intestinal absorption of ergotamine in man. Eur J Clin Pharmacol . 1974;7:213-6.

108. Evers S, Gralow I, Bauer B, et al. Sumatriptan and ergotamine overuse and drug-induced headache: a clinicoepidemiologic study. Clin Neuropharmacol. 1999;22:201-6.

109. Dahlof C. Placebo-controlled clinical trials with ergotamine in the acute treatment of migraine. [Review] [18 refs]. Cephalalgia. 1993;13:166-71.

110. Diener HC, Pfaffenrath V, Pageler L, Peil H, Aicher B. The fixed combination of acetylsalicylic acid, paracetamol and caffeine is more effective than single substances and dual combination for the treatment of headache: a multicentre, randomized, doubleblind, single-dose, placebo-controlled parallel group study. Cephalalgia. 2005;25:776-87.

111. Diener HC, Peil H, Aicher B. The efficacy and tolerability of a fixed combination of acetylsalicylic acid, paracetamol, and caffeine in patients with severe headache: a post-hoc subgroup analysis from a multicentre, randomized, double-blind, single-dose, placebo-controlled parallel group study. Cephalalgia. 2011;31: 1466-76.

112. Laska EM, Sunshine A, Mueller F, Elvers WB, Siegel C, Rubin A. Caffeine as an analgesic adjuvant. JAMA. 1984;251:1711-8.

113. Ray WA, Varas-Lorenzo C, Chung CP, et al. Cardiovascular risks of nonsteroidal antiinflammatory drugs in patients after hospitalization for serious coronary heart disease. Circulation. Circ Cardiovasc Qual Outcomes. 2009;2:155-63.

114. Fosbol EL, Folke F, Jacobsen S, et al. Cause-specific cardiovascular risk associated with nonsteroidal antiinflammatory drugs among healthy individuals. Circulation. Circ Cardiovasc Qual Outcomes. 2010;3:395-405

115. Sauro KM, Becker WJ. Multidisciplinary treatment for headache in the Canadian healthcare setting. Can J Neurol Sci. 2008;35: 46-56.

116. MacGregor EA, Victor TW, $\mathrm{Hu} \mathrm{X}$, et al. Characteristics of menstrual vs nonmenstrual migraine: a post hoc, within-woman analysis of the usual-care phase of a nonrandomized menstrual migraine clinical trial. Headache. 2010;50:528-38

117. Diamond ML, Cady RK, Mao L, et al. Characteristics of migraine attacks and responses to almotriptan treatment: a comparison of menstrually related and nonmenstrually related migraines. Headache. 2008;48:248-58

118. Mannix LK, Loder E, Nett R, et al. Rizatriptan for the acute treatment of ICHD-II proposed menstrual migraine: two prospective, randomized, placebo-controlled, double-blind studies. Cephalalgia. 2007;27:414-21.

119. Tuchman M, Hee A, Emeribe U, Silberstein S. Efficacy and tolerability of zolmitriptan oral tablet in the acute treatment of menstrual migraine. CNS Drugs. 2006;20:1019-26.

120.Pringsheim T, Davenport WJ, Dodick D. Acute treatment and prevention of menstrually related migraine headache: evidencebased review. Neurology. 2008;70:1555-63.

121. Mannix LK, Martin VT, Cady RK, et al. Combination treatment for menstrual migraine and dysmenorrhea using sumatriptannaproxen: two randomized controlled trials. Obstet Gynecol. 2009;114:106-13

122. Brandes JL, Poole A, Kallela M, et al. Short-term frovatriptan for the prevention of difficult-to-treat menstrual migraine attacks. Cephalalgia. 2009;29:1133-48

123. Silberstein SD, Elkind AH, Schreiber C, Keywood C. A randomized trial of frovatriptan for the intermittent prevention of menstrual migraine. Neurology. 2004;63:261-9.

124. Tuchman MM, Hee A, Emeribe U, Silberstein S. Oral zolmitriptan in the short-term prevention of menstrual migraine: a randomized, placebo-controlled study. CNS Drugs. 2008;22: 877-86.
125. Mannix LK, Savani N, Landy S, et al. Efficacy and tolerability of naratriptan for short-term prevention of menstrually related migraine: data from two randomized, double-blind, placebocontrolled studies. Headache. 2007;47:1037-49.

126. Sances G, Martignoni E, Fioroni L, Blandini F, Facchinetti F, Nappi G. Naproxen sodium in menstrual migraine prophylaxis: a double-blind placebo controlled study. Headache. 1990;30: 705-9.

127. MacGregor EA, Frith A, Ellis J, Aspinall L, Hackshaw A. Prevention of menstrual attacks of migraine: a double-blind placebo-controlled crossover study. Neurology. 2006;67: 2159-63.

128. Almen-Christensson A, Hammar M, Lindh-Astrand L, Landtblom AM, Brynhildsen J. Prevention of menstrual migraine with perimenstrual transdermal 17-beta-estradiol: a randomized, placebo-controlled, double-blind crossover study. Fertil Steril. 2011;96:498-500.e1.

129. Facchinetti F, Sances G, Borella P, Genazzani AR, Nappi G. Magnesium prophylaxis of menstrual migraine: effects on intracellular magnesium. Headache. 1991;31:298-301.

130.Al-Waili NS. Treatment of menstrual migraine with prostaglandin synthesis inhibitor mefenamic acid: double-blind study with placebo. Eur J Med Res. 2000;5:176-82.

131. Teichmann A, Apter D, Emerich J, et al. Continuous, daily levonorgestrel/ethinyl estradiol vs. 21-day, cyclic levonorgestrel/ ethinyl estradiol: efficacy, safety and bleeding in a randomized, open-label trial. Contraception. 2009;80:504-11.

132. Reid RL, Fortier MP, Smith L, Mirkin S, Grubb GS, Constantine GD. Safety and bleeding profile of continuous levonorgestrel 90 mcg/ethinyl estradiol $20 \mathrm{mcg}$ based on 2 years of clinical trial data in Canada. Contraception. 2010;82:497-502.

133. Coffee AL, Sulak PJ, Kuehl TJ. Long-term assessment of symptomatology and satisfaction of an extended oral contraceptive regimen. Contraception. 2007;75:444-9.

134. Sulak P, Willis S, Kuehl T, Coffee A, Clark J. Headaches and oral contraceptives: impact of eliminating the standard 7-day placebo interval. Headache. 2007; 47:27-37.

135.Loder E, Rizzoli P, Golub J. Hormonal management of migraine associated with menses and the menopause: a clinical review. Headache. 2007;47:329-40

136. Calhoun A. Combined hormonal contraceptives: is it time to reassess their role in migraine? Headache. 2012;52:648-60.

137. MacGregor EA. Contraception and headache. Headache. 2013;53: 247-76.

138. Macintyre PE, Schug SA, Scott DA, Visser EJ, Walker SM, APM: SE Working Group of the Australian and New Zealand College of Anaesthetists and Faculty of Pain Medicine. Acute pain management: scientific evidence. Melbourne: ANZA and FPM, 2010.

139. Nezvalova-Henriksen K, Spigset O, Nordeng H. Effects of codeine on pregnancy outcome: Results from a large population-based cohort study. Eur J Clin Pharmacol. 2011;67:1253-61.

140. Nezvalova-Henriksen K, Spigset O, Nordeng H. Triptan exposure during pregnancy and the risk of major congenital malformations and adverse pregnancy outcomes: results from the Norwegian Mother and Child Cohort Study. Headache. 2010;50:563-75.

141.Duong S, Bozzo P, Nordeng H, Einarson A. Safety of triptans for migraine headaches during pregnancy and breastfeeding. Can Fam Physician. 2010;56:537-9.

142. American Academy of Pediatrics Committee on Drugs. Transfer of drugs and other chemicals into human milk. Pediatrics. 2001; 108:776-89.

143. Hendrickson RG, McKeown NJ. Is maternal opioid use hazardous to breast-fed infants? Clin Toxicol (Phila). 2012;50:1-14.

144. Rossi P, Ambrosini A, Buzzi MG. Prodromes and predictors of migraine attack. Funct Neurol. 2005;20:185-91.

145. Kelman L. The premonitory symptoms (prodrome): a tertiary care study of 893 migraineurs. Headache. 2004;44:865-72.

146. Schoonman GG, Evers DJ, Terwindt GM, van Dijk JG, Ferrari MD. The prevalence of premonitory symptoms in migraine: a questionnaire study in 461 patients. Cephalalgia. 2006;26: 1209-13. 
147. Quintela E, Castillo J, Munoz P, Pascual J. Premonitory and resolution symptoms in migraine: a prospective study in 100 unselected patients. Cephalalgia. 2006;26:1051-60.

148. Giffin NJ, Ruggiero L, Lipton RB, et al. Premonitory symptoms in migraine: an electronic diary study. Neurology 2003;60:935-40.

149. Waelkens J. Dopamine blockade with domperidone: bridge between prophylactic and abortive treatment of migraine? A dose-finding study. Cephalalgia. 1984;4:85-90.

150.Luciani R, Carter D, Mannix L, Hemphill M, Diamond M, Cady R. Prevention of migraine during prodrome with naratriptan. Cephalalgia. 2000;20:122-6.

151. Waelkens J. Domperidone in the prevention of complete classical migraine. Br Med J (Clin Res Ed). 1982;284:944.

152. Becker WJ. The premonitory phase of migraine and migraine management. Cephalalgia. 2012 Feb 15; [Epub ahead of print].

153. Jelinski SE, Becker WJ, Christie SN, et al. Clinical features and pharmacological treatment of migraine patients referred to headache specialists in Canada. Cephalalgia. 2006;26:578-88.

154.Derry S, Moore RA, McQuay HJ. Paracetamol (acetaminophen) with or without an antiemetic for acute migraine headaches in adults. Cochrane Database Syst Rev. 2010;008040.

155.Lipton RB, Grosberg B, Singer RP, et al. Efficacy and tolerability of a new powdered formulation of diclofenac potassium for oral solution for the acute treatment of migraine: results from the International Migraine Pain Assessment Clinical Trial (IMPACT). Cephalalgia. 2010;30:1336-45.
156. Buchan P, Keywood C, Wade A, Ward C. Clinical pharmacokinetics of frovatriptan. Headache. 2002;42:S54-62.

157. Johnston MM, Rapoport AM. Triptans for the management of migraine. Drugs. 2010;70:1505-18.

158. Derry CJ, Derry S, Moore RA. Sumatriptan (subcutaneous route of administration) for acute migraine attacks in adults. Cochrane Database Syst Rev. 2012;2:009665.

159. Derry CJ, Derry S, Moore RA. Sumatriptan (intranasal route of administration) for acute migraine attacks in adults. Cochrane Database Syst Rev. 2012;2:009663.

160. Pascual J, Falk RM, Piessens F, et al. Consistent efficacy and tolerability of almotriptan in the acute treatment of multiple migraine attacks: results of a large, randomized, double-blind, placebo-controlled study. Cephalalgia. 2000;20:588-96.

161. Rapoport A, Ryan R, Goldstein J, Keywood C. Dose range-finding studies with frovatriptan in the acute treatment of migraine. Headache. 2002;42:S74-83.

162. Derry CJ, Derry S, Moore RA. Sumatriptan (oral route of administration) for acute migraine attacks in adults. Cochrane Database Syst Rev. 2012;2:008615.

163. Pryse-Phillips WE, Dodick DW, Edmeads JG, et al. Guidelines for the diagnosis and management of migraine in clinical practice. Canadian Headache Society. [see comment][erratum appears in CMAJ 1997 Nov 15;157(10):1354]. [Review] [160 refs]. CMAJ. $1997 ; 156: 1273-87$ 